\title{
Management of acute upper gastrointestinal bleeding
}

\author{
Adrian J Stanley, ${ }^{1}$ Loren Laine ${ }^{2}$
}

${ }^{1}$ Department of Gastroenterology, Glasgow Royal Infirmary, Glasgow G4 OSF, UK

${ }^{2}$ Section of Digestive Diseases, Yale School of Medicine, New Haven, and VA Connecticut Healthcare System, West Haven, Connecticut, CT 06520, USA

Correspondence to: A J Stanley adrian.stanley@ggc.scot.nhs.uk and adrianstanley99@gmail.com Cite this as: BMJ 2019;364:1536 doi: $10.1136 /$ bmj.l536

Series explanation: State of the Art Reviews are commissioned on the basis of their relevance to academics and specialists in the US and internationally. For this reason they are written predominantly by US authors

\begin{abstract}
Upper gastrointestinal bleeding (UGIB) is a common medical emergency, with a reported mortality of $2-10 \%$. Patients identified as being at very low risk of either needing an intervention or death can be managed as outpatients. For all other patients, intravenous fluids as needed for resuscitation and red cell transfusion at a hemoglobin threshold of 70-80 $\mathrm{g} / \mathrm{L}$ are recommended. After resuscitation is initiated, proton pump inhibitors (PPIs) and the prokinetic agent erythromycin may be administered, with antibiotics and vasoactive drugs recommended in patients who have cirrhosis. Endoscopy should be undertaken within 24 hours, with earlier endoscopy considered after resuscitation in patients at high risk, such as those with hemodynamic instability. Endoscopic treatment is used for variceal bleeding (for example, ligation for esophageal varices and tissue glue for gastric varices) and for high risk non-variceal bleeding (for example, injection, thermal probes, or clips for lesions with active bleeding or non-bleeding visible vessel). Patients who require endoscopic therapy for ulcer bleeding should receive high dose proton pump inhibitors after endoscopy, whereas those who have variceal bleeding should continue taking antibiotics and vasoactive drugs. Recurrent ulcer bleeding is treated with repeat endoscopic therapy, with subsequent bleeding managed by interventional radiology or surgery. Recurrent variceal bleeding is generally treated with transjugular intrahepatic portosystemic shunt. In patients who require antithrombotic agents, outcomes appear to be better when these drugs are reintroduced early
\end{abstract}

\section{Introduction}

Upper gastrointestinal bleeding is a common medical emergency worldwide and refers to bleeding from the esophagus, stomach, or duodenum. Patients present with hematemesis (bloody or coffee ground emesis) or melena, although hematochezia can occur in the context of a major bleed and is typically associated with hemodynamic instability. Patients with melena present with lower hemoglobin values than patients with hematemesis, probably because presentation is more likely to be delayed. ${ }^{1}$ Therefore, patients with melena more often require transfusion, although mortality is lower in patients with melena than in those with hematemesis in some series. ${ }^{1}$ Numerous improvements in the management of upper gastrointestinal bleeding have been incorporated into clinical practice in recent years. However, many patients now have risk factors for a poorer outcome, including increasing age and major medical comorbidities. ${ }^{2}$

Although the cause of a bleeding episode is uncertain until endoscopy is undertaken, guidelines often separate upper gastrointestinal bleeding into variceal and nonvariceal bleeding because management and outcomes differ. $^{3-9}$ This article covers the acute management of patients with overt upper gastrointestinal bleeding, summarizing evidence for risk assessment, resuscitation, blood transfusion, medical and endoscopic therapy, and early post-endoscopic management. We will not review interventions for long term secondary prevention of bleeding, such as testing for and treating Helicobacter pylori infection, use of non-steroidal anti-inflammatory drugs (NSAIDs), or maintenance antisecretory therapy.

Upper gastrointestinal bleeding is managed by many clinicians across many specialties, including emergency room physicians, hospitalists, internists, gastroenterologists, surgeons, interventional radiologists, and hematologists.

A variety of topics-including risk assessment, the threshold for blood transfusion, the timing of endoscopy, and medical and endoscopic therapies-have continued to evolve in recent years. In addition, it has become increasingly important and complex to determine the appropriate management of patients who need antithrombotic agents, with gastroenterological, cardiovascular, and hematological aspects needing to be considered.

This article provides a comprehensive and evidence based summary of the assessment and management of patients with acute upper gastrointestinal bleeding, which is relevant to clinician specialists, academics, and clinical researchers. A summary of management is provided in the box. 


\section{SUMMARY OF THE MANAGEMENT OF UPPER GASTROINTESTINAL BLEEDING}

\section{Pre-endoscopic management}

- Hemodynamic assessment and resuscitation as needed

- Blood transfusion at a hemoglobin threshold of 70-80 g/L; higher threshold if severe bleeding with hypotension

- Risk assessment:

-If Glasgow-Blatchford score $\leq 1$ consider outpatient endoscopy and management

- Erythromycin (as a prokinetic agent) and proton pump inhibitor may be considered

- Patients with cirrhosis should receive vasoactive drugs and antibiotics

Endoscopic

- Endoscopy is generally recommended within 24 hours in patients admitted to hospital - If the patient has severe bleeding with hemodynamic instability, urgent endoscopy should be performed after resuscitation

- Ulcers with active bleeding and non-bleeding visible vessels should receive endoscopic therapy; endoscopic therapy may also be used for ulcers with adherent clots

- Injection therapy (eg, epinephrine), thermal probes (eg, bipolar electrocoagulation, heater probe), or clips should be used

- Epinephrine injection should always be followed by a second modality

- Recurrent bleeding should be treated with repeat endoscopic therapy but subsequent bleeding by transarterial embolization or surgery

- Esophageal variceal bleeding should be treated with ligation and gastric varices with the injection of tissue adhesive

- Refractory variceal bleeding should be treated with transjugular portosystemic shunt

- For massive refractory esophageal variceal bleeding a removable covered metal stent is preferred to balloon tamponade as a temporizing measure

Post-endoscopic management

- Patients who have ulcers with high risk lesions (active bleeding, visible vessel, adherent clot) should receive high dose proton pump inhibitors for $72 \mathrm{~h}$

- Patients with cirrhosis should continue antibiotics for up to seven days regardless of the bleeding source

- Variceal bleeding should be treated with vasoactive drugs for up to five days

- When used for secondary prevention, aspirin should be continued or reintroduced soon after hemostasis is achieved

- Early reintroduction of other antithrombotic drugs is also recommended after hemostasis is achieved to reduce thrombotic events and death

\section{Overall quality of evidence}

Numerous randomized controlled trials (RCTs) and meta-analyses have assessed the use of medical and endoscopic therapy, and the optimal blood transfusion strategy in patients with acute upper gastrointestinal bleeding, thereby providing high quality data to guide management. Although the evidence regarding resuscitation, risk assessment, timing of endoscopy, and reintroduction of antithrombotic drugs is of lower quality, large recent studies in these areas have helped inform patient management.

\section{Incidence}

The incidence of upper gastrointestinal bleeding in the United Kingdom in the 1990s was 103-172/100 000 adults per year. ${ }^{1011}$ Recent reports from the United States using nationwide administrative databases indicate that the incidence of hospital admission for the condition was 61-78 per 100000 persons in 2009-2012. ${ }^{12-14}$ Peptic ulcers are the most common cause of hospital admission for upper gastrointestinal bleeding, accounting for just over half of all cases. ${ }^{1214}$ The incidence of hospital admission for the condition has decreased $21-23 \%$ during the past 10 years. ${ }^{1214}$ This decrease is largely accounted for by decreases in peptic ulcer bleeding (and bleeding ascribed to "gastritis") probably because of the decreasing prevalence of $H$ pylori and increasing use of antisecretory drugs. Case fatality rates from these database studies were low, in the range of 1.9-2.5\%. ${ }^{12-14}$ By contrast, large observational cohort studies from Europe suggest higher fatality rates of around $10 \% .{ }^{15}{ }^{16}$ The reason for these differences is unknown but might be partly related to reliance on coding in database studies and differences in practice, such as low risk patients being more often managed in outpatient settings in Europe.

\section{Sources and selection criteria}

We searched PubMed, Medline, and Cochrane databases from 2010 to August 2018 using the search terms gastrointestinal hemorrhage, peptic ulcer bleeding, and variceal bleeding. References were also identified from the international, UK, European, American, and Asia-Pacific guidelines on upper gastrointestinal bleeding published during this period in addition to relevant review articles. We selected systematic reviews, meta-analyses, RCTs, and observational studies (excluding case reports and small ( $<15$ cases) case series). We also excluded articles that were not peer reviewed and those not published in English. Studies were prioritized by design, as noted above, and by patient numbers, quality, and publication date.

\section{Initial resuscitation}

As with any new patient with a medical emergency, the initial clinical evaluation of patients presenting with upper gastrointestinal bleeding involves assessment of the patient's airway, breathing, and circulation. Many patients are hemodynamically stable at presentation, but for those with major bleeding, early resuscitation is essential. In general, two large bore intravenous cannulae are inserted, although central venous access may be preferred in certain cases. Regular monitoring of pulse, blood pressure, and oxygen saturations is crucial. Hypotension is associated with increased mortality; a multicenter observational study of 1882 patients reported an odds ratio of 9.8 (95\% confidence interval 5.1 to 19$)$ with systolic blood pressure $<90 \mathrm{~mm} \mathrm{Hg}$ versus $\geq 90 \mathrm{~mm} \mathrm{Hg}$. ${ }^{11}$ Tracheal intubation may be used to protect the airway in patients with severe ongoing hematemesis, especially in those at increased risk of aspiration (such as those with an altered mental status or lack of gag reflex).

No RCTs have assessed fluid resuscitation in upper gastrointestinal bleeding. By contrast, a comparative study and an RCT in patients with hemorrhagic shock as a result of trauma suggest that a more restrictive fluid resuscitation may be better (or not worse) than more intensive fluid resuscitation. ${ }^{1718}$ The choice of intravenous fluid for initial resuscitation is unclear, with crystalloids or colloids often being used while the need for the transfusion of blood products is assessed. A meta-analysis of 70 trials with 22392 patients found no difference in mortality between colloid and crystalloid solutions for fluid resuscitation in critically ill patients: relative risk 1.01 (0.93 to 1.10) for albumin or plasma proteins versus crystalloid solutions, and similar negative results when other colloids were compared with crystalloids. ${ }^{19}$ An RCT of 15 802 critically ill hospital inpatients found reduced acute 

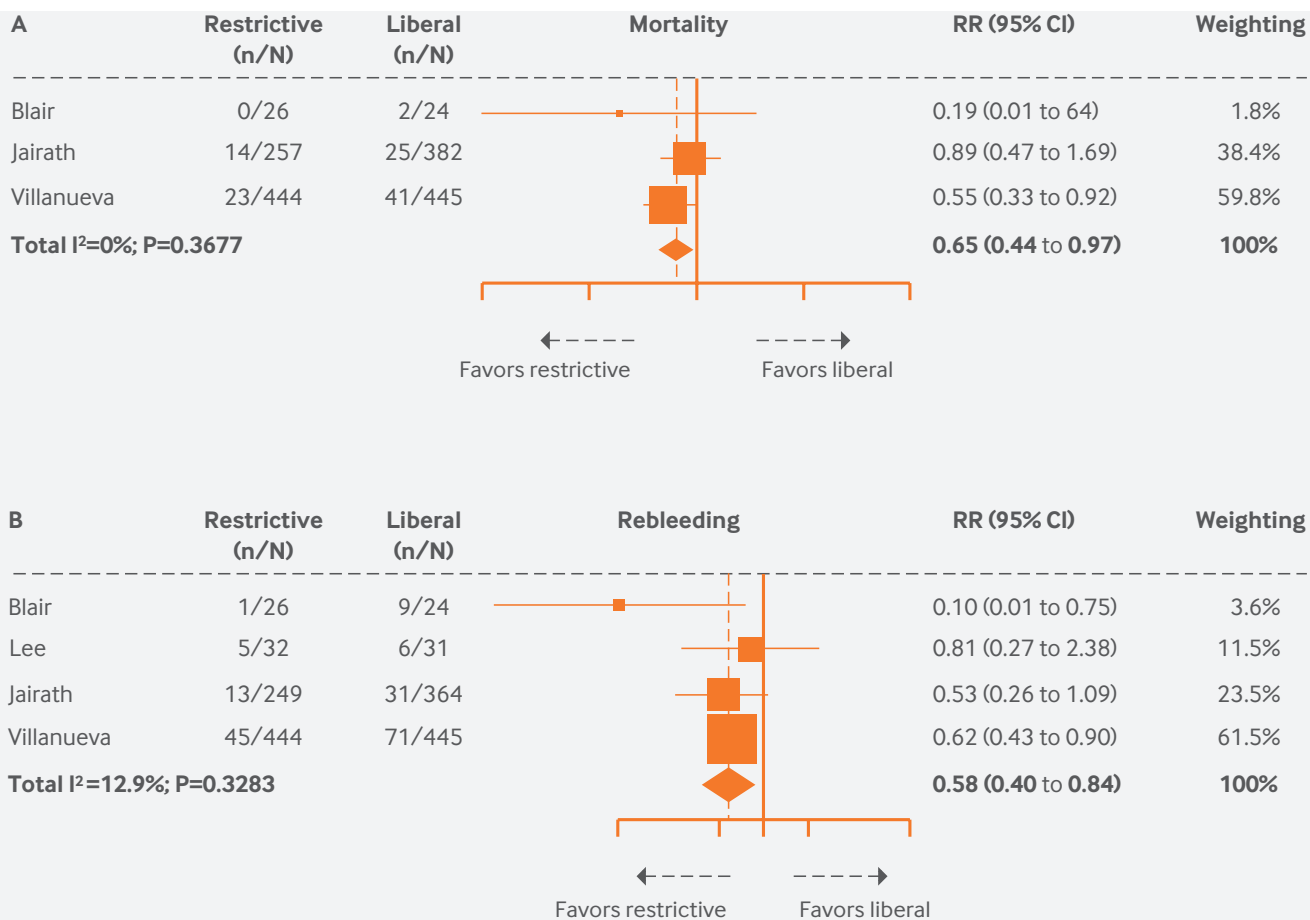

Fig 1 | Blood transfusion meta-analysis: liberal versus restrictive transfusion for (A) mortality and (B) rebleeding. ${ }^{27}$ Reproduced with permission from Elsevier. Abbreviations: $\mathrm{Cl}=$ confidence interval; $\mathrm{RR}=$ relative risk.

kidney injury (odds ratio $0.91,0.84$ to 0.99 ) and a trend towards reduced mortality in hospital $(10.3 \% v 11.1 \%$; $\mathrm{P}=0.08$ ) with balanced crystalloids versus saline. ${ }^{20}$ Whether these data can be fully extrapolated to upper gastrointestinal bleeding is uncertain.

\section{Red blood cell transfusion}

A meta-analysis of 31 RCTs comprising 12587 patients in a variety of populations found that a more restrictive approach to red cell transfusion (variably defined at hemoglobin threshold 70-90 g/L) does not adversely affect outcomes; hospital mortality was lower with a restrictive strategy but 30 day mortality was not significantly different (risk ratio $0.97,0.81$ to 1.16 ). ${ }^{21}$ This systematic review concluded that a restrictive policy seemed to be safe in patients with underlying cardiovascular disease but no evidence was available for patients presenting with acute coronary syndrome. On that basis, current US guidelines recommend transfusion at a threshold of hemoglobin of $70 \mathrm{~g} / \mathrm{L}$ for hemodynamically stable adult inpatients and $80 \mathrm{~g} / \mathrm{L}$ for those undergoing orthopedic or cardiac surgery or with pre-existing cardiovascular disease. ${ }^{22}$ Others have suggested a threshold in patients with cardiovascular disease of $\geq 80 \mathrm{~g} / \mathrm{L}$. ${ }^{23}$

Importantly, results for the general populations described above may not be applicable to those with upper gastrointestinal bleeding. In such patients a restrictive transfusion approach appears not only to be safe but also to provide clinical benefit for rebleeding and mortality. A small study in 1986 first showed reduced rebleeding with restrictive transfusion. ${ }^{24} \mathrm{~A}$ large high quality Spanish RCT in 921 patients found significantly lower mortality at six weeks (hazard ratio $0.55,0.33$ to 0.92 ) and rebleeding $(0.68,0.47$ to 0.98$)$ with a transfusion hemoglobin thresh- old of $70 \mathrm{~g} / \mathrm{L}$ versus $90 \mathrm{~g} / \mathrm{L} .{ }^{25}$ A subsequent six center cluster randomized feasibility trial in the UK reported no benefit from a liberal transfusion policy when hemoglobin thresholds of $80 \mathrm{~g} / \mathrm{L}$ versus $100 \mathrm{~g} / \mathrm{L}$ were compared (mortality difference $-1 \%,-8 \%$ to $6 \%$ in 640 patients). ${ }^{26} \mathrm{~A}$ meta-analysis of five RCTs comprising 1965 patients with upper gastrointestinal bleeding reported that restrictive transfusion was associated with lower mortality (relative risk $0.65,0.44$ to 0.97$)$ and reduced rebleeding $(0.58$, 0.40 to 0.84 ) (fig 1$).^{27}$

Thus, in most patients with upper gastrointestinal bleeding, red cell transfusion should be withheld until a hemoglobin threshold of $70-80 \mathrm{~g} / \mathrm{L}$ is reached..$^{5628}$ Patients with severe bleeding and hemodynamic compromise, who were generally excluded from the trials described above, require transfusion at higher thresholds because their hemoglobin will equilibrate to much lower levels as their intravascular volume is repleted with fluid. Transfusion thresholds in patients with cardiovascular disease, especially those with acute coronary syndrome, are less certain, but thresholds of $80 \mathrm{~g} / \mathrm{L}$ or higher are variably recommended. ${ }^{22} 23$

\section{Risk assessment}

Many risk assessment scores have been developed for patients with upper gastrointestinal bleeding, including those that can be calculated early after presentation (pre-endoscopy) and those that include endoscopic findings. ${ }^{29-34}$ They were designed to predict a variety of endpoints. We believe pre-endoscopy scores are of greater practical use because it is probably most important to predict risk soon after presentation to help direct management. The use of risk scores has been recommended to stratify patients into those at higher or lower risk of poor 


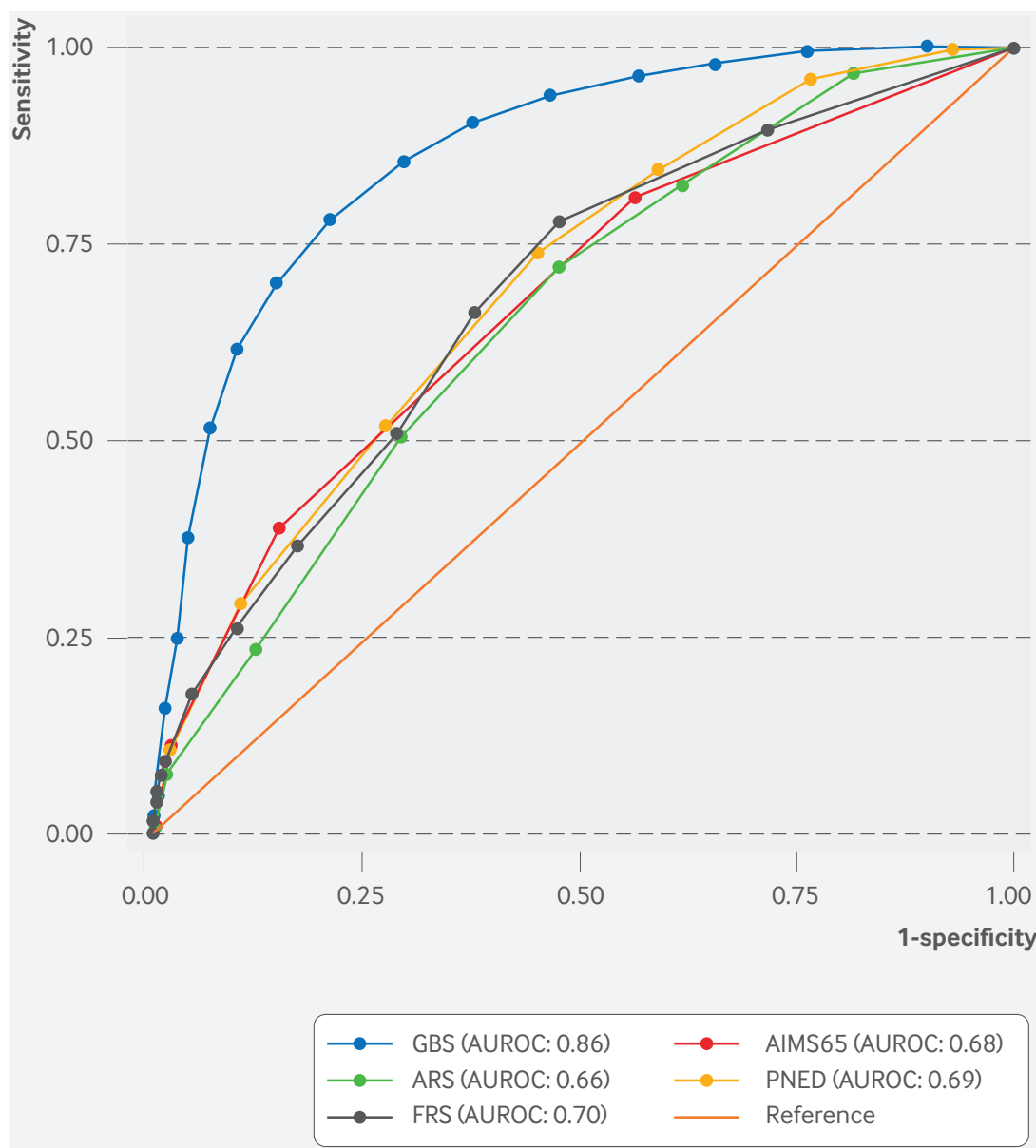

Fig 2 Comparison of five upper gastrointestinal bleeding risk scores in prediction of the need for any intervention (transfusion, endoscopic therapy, interventional radiology, or surgery) or 30 day mortality $(n=1704) .{ }^{35}$ Abbreviations: $A$ IMS $65=$ see text; $A R S=a d m i s s i o n$ Rockall score; $A U R O C=$ area under the receiver operating characteristic curve; $F R S=$ full Rockall score; GBS=Glasgow Blatchford score; $\mathrm{PNED}=$ Progetto Nazionale Emorragia digestive score.

outcome. ${ }^{36}$ This enables patients predicted to be high risk to be managed in high dependency or intensive care units and receive urgent endoscopy, whereas those at very low risk can be managed as outpatients.

The most well established and commonly used preendoscopic scores are the Glasgow Blatchford score (GBS), the pre-endoscopic or "admission" Rockall score, and the AIMS65score (Albumin $<3 \mathrm{mg} / \mathrm{dL}$, International normalized ratio $>1.5$, altered Mental status, Systolic blood pressure $<90 \mathrm{~mm} \mathrm{Hg}$, age $>65$ years)..$^{293234}$ The GBS was developed to predict a composite of clinical intervention or death, whereas the other two were designed to predict death. Many studies have compared these and other scores, and GBS seems to be superior at predicting a combined endpoint of intervention or death (fig 2). ${ }^{35-37}$

These risk assessment scores cannot precisely identify individual high risk patients who will definitely die if they do not receive the intervention. Therefore, they have limited clinical utility for predicting which patients are at higher risk. However, risk scores do seem to have a clinical role in identifying patients who are at very low risk. ${ }^{38}$ When aiming to identify a cohort of patients who are at very low risk and could be managed as outpatients, it is important to achieve a very high sensitivity so that almost no patients who may come to harm are sent home.

A systematic review of 16 studies on the use of preendoscopy scores in emergency departments to predict intervention, rebleeding, or death concluded that a GBS of zero provided the highest sensitivity (0.99), although specificity was very low (0.08).$^{39}$ In 2012, both US and UK guidelines recommended that a GBS of zero could be used to identify very low risk patients who could avoid admission and be offered outpatient endoscopy. ${ }^{428}$

Subsequently two large international comparative studies of risk assessment scores, with 3012 and 2305 patients, were published..$^{350}$ These studies reported that GBS $\leq 1$ was the optimum low risk threshold, with a sensitivity of $99 \%$ and specificity of $35-40 \%$. The authors suggested that this threshold could be used to identify patients who could be safely discharged from the emergency department for outpatient management, thereby avoiding admission in $19-24 \%$ of patients presenting with upper gastrointestinal bleeding. This approach has been accepted by recent European and Asia-Pacific guidelines. ${ }^{56}$ No high quality interventional trial has assessed outcomes after the introduction of a risk score, although a pre-post design study showed the safety of outpatient management in 84 patients with a GBS score of zero. ${ }^{38}$

\section{Management of patients taking antithrombotic drugs}

The increasing use of antiplatelet and anticoagulant (antithrombotic) medication in the management of cardiovascular disease means that many patients now presenting with upper gastrointestinal bleeding are taking these drugs. A recent multicenter observational study of 619 patients requiring endoscopic therapy for upper gastrointestinal bleeding reported that $44 \%$ were taking an antithrombotic drug at presentation, with $25 \%$ taking more than one. ${ }^{41}$ Although these drugs are a recognized risk factor for upper gastrointestinal bleeding, ${ }^{42}{ }^{43}$ no clear evidence indicates that their use worsens outcomes after the bleed. ${ }^{4144}$

The 2016 US guideline on management of antithrombotic agents for patients undergoing endoscopy suggests that platelet transfusion is an option for life threatening or serious bleeding in patients taking antiplatelet agents. ${ }^{45}$ However, observational studies have failed to identify clinical benefit, and a cohort study with 408 patients showed significantly higher mortality with platelet transfusion (odds ratio 5.6, 1.5 to 27.1). ${ }^{46}$ This finding led the recent Asia-Pacific guideline panel to suggest that platelet transfusions should not be used in patients taking antiplatelet agents who present with upper gastrointestinal bleeding. ${ }^{6}$ Platelet dysfunction may also be present in patients on hemodialysis or those who have had cardiac bypass surgery. ${ }^{47}$

Less information is available regarding the management of anticoagulants, including warfarin and the newer direct oral anticoagulants (DOACs), in patients with upper gastrointestinal bleeding. For patients taking warfarin, recent guidelines suggested the use of prothrombin complex concentrate (PCC) along with vitamin K to prevent rebound coagulopathy in patients with a life threatening bleed or hemodynamic instability. ${ }^{56}$ PCC is preferable 
to fresh frozen plasma because of the smaller volume needed, its more rapid onset, lack of the need to check the patient's blood group, and the minimal infectious risk. ${ }^{5}$ US guidelines suggest either four factor PCC plus vitamin $\mathrm{K}$ or fresh frozen plasma. ${ }^{45}$

Guidelines also suggest that the international normalized ratio (INR) should be corrected to $<2.5$ if possible before undertaking endoscopy, with the potential need for endoscopic therapy if the clinical situation allows. ${ }^{545}$ This suggestion is based on observational studies which indicate that the outcome after endoscopic therapy is similar in patients with an INR of 1.3-2.7 to that in those not taking warfarin..$^{4849}$ Other studies report that the INR value does not predict rebleeding. ${ }^{50}$

Data on DOACs are limited, but because of their short half lives (5-17 h), anticoagulant activity wanes rapidly over one to two days (in the absence of renal disease). Thus, European guidelines state that "time is the most important antidote against DOACs." Although PCC may be of some use in severe bleeding, particularly for Xa inhibitors, neither vitamin $\mathrm{K}$ nor fresh frozen plasma has been shown to be beneficial. ${ }^{5{ }^{51}}$ Reversal agents for dabigatran (idarucizumab) ${ }^{52}$ and the factor Xa inhibitors (andexanet alfa) ) $^{53}$ are now approved in the US. Their role in patients with upper gastrointestinal bleeding is unclear given the uncertain risk of thrombotic events and the short half lives of DOACS. They would mainly be used in patients with a severe ongoing bleed, especially if DOAC ingestion was recent or if renal disease was present.

\section{Coagulopathy and thrombocytopenia in patients with cirrhosis}

Interpretation of the complex clotting abnormalities seen in cirrhosis can be difficult. Patients with cirrhosis have parallel decreases in procoagulant and anticoagulant factors. ${ }^{54}$ The prothrombin time measures procoagulant activity only; therefore, prothrombin time or INR is not a reliable indicator of coagulation status in patients with cirrhosis. ${ }^{54}$ Fresh frozen plasma is often given to patients with upper gastrointestinal bleeding, cirrhosis, and raised prothrombin time, but it has not been shown to provide benefit and could have adverse effects. For these reasons, the most recent US guidelines on portal hypertensive bleeding recommend against correcting INR with fresh frozen plasma or recombinant factor VIIa in patients with cirrhosis and acute variceal bleeding. ${ }^{9}$

Platelets from patients with cirrhosis generate thrombin in a similar way to those from healthy controls, and patients with cirrhosis have pro-hemostatic factors (increased von-Willebrand factor and decreased ADAMTS-13, a protease that cleaves von-Willebrand factor) ${ }^{5455}$ However, patients with cirrhosis often have thrombocytopenia as a result of splenic sequestration. The experimental finding that a platelet count of $56 \times 10^{9} /$ L leads to thrombin generation at the 10 th centile of healthy control values ${ }^{54}$ provides the basis for giving platelet transfusions at around $50 \times 10^{9} / \mathrm{L} .{ }^{47}$ However, no studies have assessed platelet thresholds or results with platelet transfusions, and some current guidelines state that no recommendation can be made regarding platelet transfusions. ${ }^{89}$

\section{Pre-endoscopic medical therapy}

The use of pre-endoscopic intravenous proton pump inhibitors (PPIs) has been assessed in several studies. A meta-analysis of six RCTs comprising 2223 patients found that the use of these drugs before endoscopy is associated with both reduced high risk stigmata of bleeding and the need for endoscopic therapy (odds ratio $0.68,0.50$ to 0.93) but has no effect on patient outcomes, including rebleeding, need for surgery, or mortality $(1.12,0.72$ to 1.73). ${ }^{56}$ As a result, UK National Institute for Health and Care Excellence (NICE) guidelines do not support the routine use of these drugs before endoscopy. ${ }^{4}$ However, several other international guidelines suggest PPIs may have a role before endoscopy, particularly for patients in whom endoscopy may be delayed. ${ }^{3562857}$

Prokinetic agents have been assessed for their ability to improve gastric emptying, thereby improving visualization at endoscopy. Erythromycin, usually given as a $250 \mathrm{mg}$ infusion 30-120 minutes before endoscopy, has been most widely studied. The most recent meta-analysis of 598 patients in eight RCTs showed improved visualization, reduced need for second look endoscopy, and reduced length of hospital stay (mean difference -1.75 days, 2.43 to -1.06 ) after erythromycin infusion before endoscopy. ${ }^{58}$

Tranexamic acid (TXA) inhibits the fibrinolytic activity of plasmin. A meta-analysis reported reduced mortality with TXA in patients with upper gastrointestinal bleeding, but many studies were of poor quality and had been undertaken before the widespread use of PPIs and endoscopic therapy. ${ }^{59}$ Furthermore, other outcomes such as bleeding episodes and transfusions were not reduced. Therefore, it is difficult to draw firm conclusions from these data. A meta-analysis of two RCTs comprising 40138 patients with acute severe traumatic or postpartum bleeding suggested even a short delay in the administration of TXA reduces benefit: immediate treatment improved survival (odds ratio 1.72, 1.42 to 2.10 ), but survival fell $10 \%$ with every 15 minutes delay, with no benefit beyond three hours. ${ }^{60} \mathrm{~A}$ large international study (HALT-IT) will finish recruitment shortly and the results should help clarify the role of TXA in upper gastrointestinal bleeding. ${ }^{61}$

\section{Pre-endoscopic medical therapy in patients with cirrhosis}

Vasoactive drugs (terlipressin, somatostatin, or its analogs octreotide and vapreotide), which cause splanchnic artery vasoconstriction, are used in patients with cirrhosis and variceal bleeding. When combined with endoscopic therapy, the different vasoactive drugs seem to have similar efficacy. ${ }^{62}$ Three double blind RCTs examined the use of vasoactive drugs (terlipressin, somatostatin, and vapreotide) given before endoscopy in patients with cirrhosis and upper gastrointestinal bleeding. ${ }^{63-65}$ Two studies reported less active bleeding at endoscopy in the active treatment group, ${ }^{6465}$ and the third noted significantly more control of bleeding (clear gastric lavage and stable hemoglobin) at 12 hours with vasoactive drug therapy. ${ }^{63}$

Current guidelines recommend starting vasoactive drugs as soon as variceal hemorrhage is suspected. ${ }^{7-9}$ 

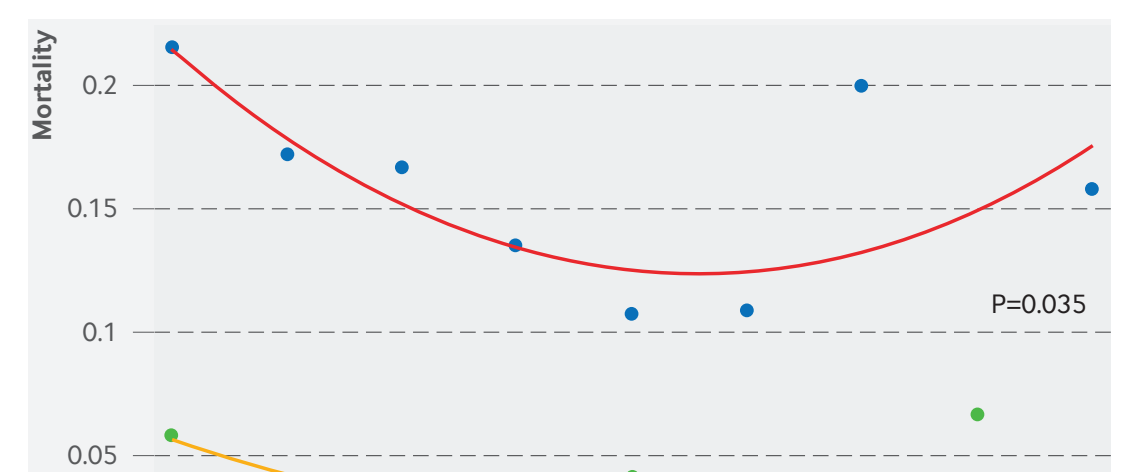

$--$

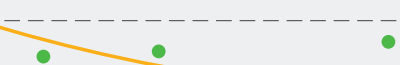

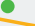

$\bullet$

$0--------------$

10

- ASA 1-2

- ASA 3-5

Fitted values

Fig 3 Association between timing of endoscopy and mortality in hospital patients with hemodynamic instability after correction for confounding variables. ${ }^{76}$ Abbreviation: ASA=American Society of Anesthesiologists score.

PPIs should not be given concurrently to patients who are receiving somatostatin (or analogs) because somatostatin provides inhibition of gastric acid secretion comparable to that provided by PPIs. ${ }^{6667}$ Recommended doses are terlipressin $2 \mathrm{mg}$ every four hours, somatostatin 250 $\mu \mathrm{g}$ bolus followed by $250-500 \mu \mathrm{g} / \mathrm{h}$, and octreotide and vapreotide $50 \mu \mathrm{g}$ bolus followed by $50 \mu \mathrm{g} / \mathrm{h}$. ${ }^{9}$ These drugs are generally given for up to five days. ${ }^{7-9}$

A meta-analysis of 12 RCTs compromising 1241 patients showed that antibiotics reduce infections, rebleeding, and mortality (relative risk $0.79,0.63$ to 0.98 ) in patients with cirrhosis and upper gastrointestinal bleeding. ${ }^{68}$ An RCT comparing intravenous ceftriaxone versus oral norfloxacin for seven days in 111 patients with advanced cirrhosis and gastrointestinal bleeding showed reduced proven infections with ceftriaxone $(11 \%$ $v 26 \%$; $\mathrm{P}=0.03) .{ }^{69}$ However, the results may not be generalizable to all patients with cirrhosis because only $9 \%$ of screened patients were enrolled. Current guidelines suggest that antibiotics should be given from admission for up to seven days. ${ }^{7-9}$ Intravenous ceftriaxone is preferred in patients with advanced cirrhosis or those taking quinolone prophylaxis and those in areas of high quinolone resistance, although the choice of antibiotic is dependent on local antimicrobial sensitivity patterns. ${ }^{7-9}$

\section{Role of non-endoscopic diagnostic modalities before endoscopy}

Because upper gastrointestinal bleeding can be diagnosed and treated with endoscopy, which is available in most hospitals, the role of other diagnostic modalities in patients presenting with an acute bleed is limited. In almost all cases, the initial diagnostic test will be upper endoscopy. Rarely, angiography or computed tomogra- phy is used in patients who are not candidates for endoscopy. However, these investigations are most commonly used if no source of bleeding is identified at endoscopy in patients with melena. A technetium-99m labelled red cell scan may also be used in this situation, but computed tomography angiography seems to be more accurate. ${ }^{7071}$ Early use of capsule endoscopy has been reported, with goals including stratifying risk and determining the timing of endoscopy, ${ }^{72}$ but more studies are needed to establish any potential role.

\section{Timing of endoscopy}

On the basis of improved outcomes in observational studies, ${ }^{3528}$ guidelines recommend that, after appropriate resuscitation, most patients who are admitted with upper gastrointestinal bleeding should undergo endoscopy within 24 hours. Some guidelines suggest that patients with hemodynamic compromise and those with cirrhosis, who may have varices, undergo endoscopy within 12 hours after presentation, ${ }^{58928}$ because some observational studies and subgroup analysis of an RCT provided limited evidence of improved outcome in high risk patients when endoscopy is performed within six to 13 hours. ${ }^{73-75}$ Features that have been considered high risk include GBS $\geq 8-12$, bloody gastric lavage or persistent bloody emesis in hospital, hypotension, tachycardia, and comorbidities such as cirrhosis. However, evidence that can precisely identify high risk patients who should undergo early endoscopy is not available. In general, patients with persistent hemodynamic instability despite aggressive resuscitation will require urgent endoscopy.

Endoscopy should not be undertaken before the patient's hemodynamic status is dealt with by initiating appropriate resuscitation and aiming to optimize comorbidities. This is illustrated by a recent observational study of 12601 Danish patients with upper gastrointestinal bleeding secondary to peptic ulcers. This study suggested a survival benefit from delaying endoscopy for 12 hours in hemodynamically stable patients with American Society of Anesthesiologists score 3-5 (odds ratio 0.48, 0.34 to 0.67 ), and for six hours in patients with hemodynamic instability $\left(0.73,0.54\right.$ to 0.98 ) (fig 3). ${ }^{76}$ Most deaths after upper gastrointestinal bleeding are caused by underlying comorbidities rather than exsanguination, so attention to other medical problems is key to patient management. ${ }^{77}$

Two small RCTs compared urgent $(<2-6 \mathrm{~h})$ with elective ( $>48 \mathrm{~h}$ ) endoscopy for patients presenting with upper gastrointestinal bleeding who were hemodynamically stable and had no serious comorbidities. ${ }^{7879}$ As expected in these low risk patients, no difference in clinical outcomes was identified. However, $\sim 40-45 \%$ of patients had low risk endoscopic findings that would allow for early discharge. Thus, non-emergent endoscopy, undertaken as soon as possible within routine business hours, is recommended in low risk patients to allow safe early discharge in many of these patients. ${ }^{80}$

\section{Endoscopic therapy}

\section{Non-variceal bleeding}

Recommended modalities for ulcer bleeding include injection of epinephrine (eg, 1:10000 dilution), injection 

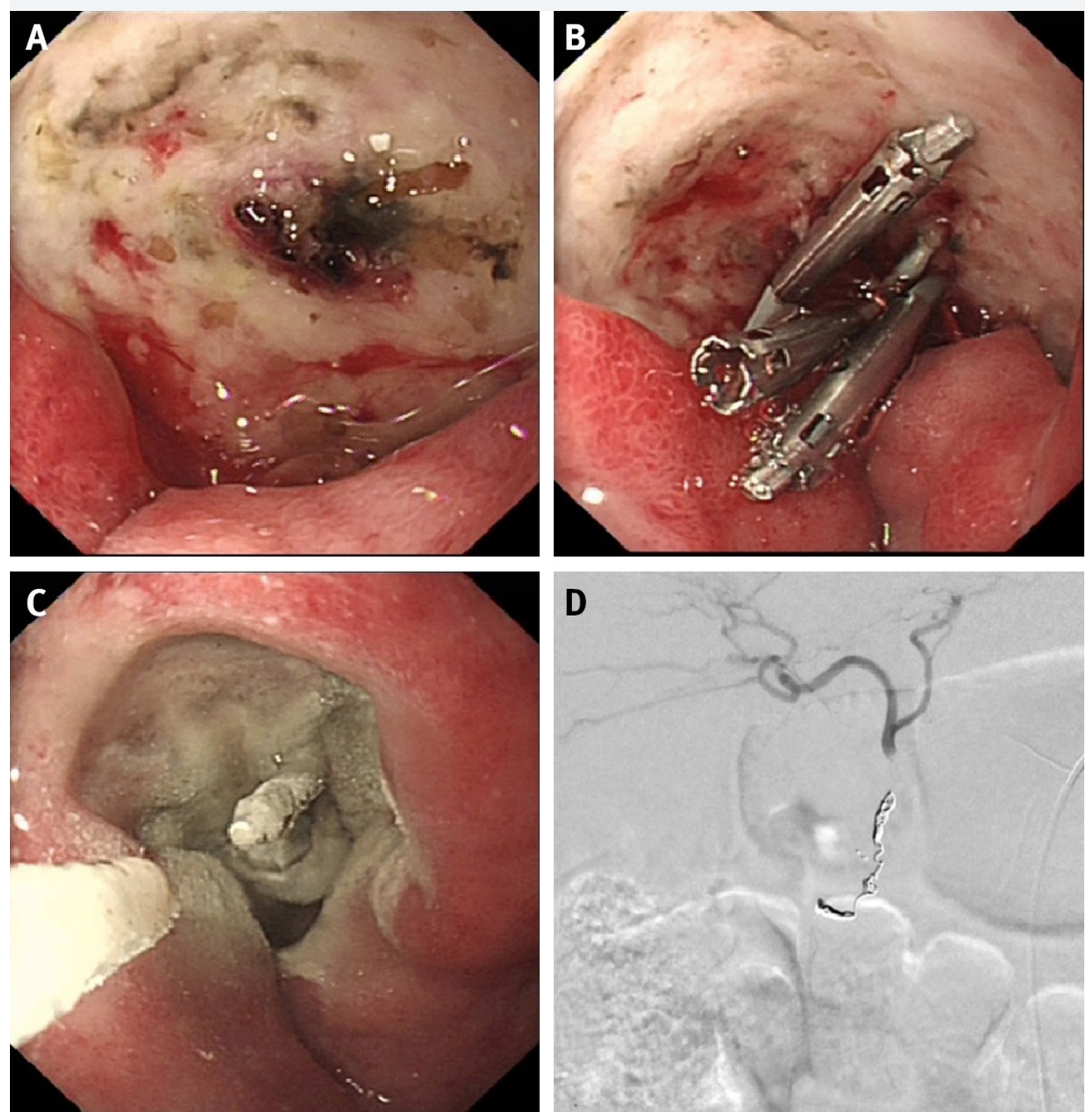

Fig 4 | (A) Endoscopic view of a large posterior duodenal ulcer with intermittent bleeding from a visible vessel. The patient, a middle aged man taking anticoagulant drugs, was admitted with hematemesis, hemodynamic instability, and a hemoglobin concentration of $55 \mathrm{~g} / \mathrm{L}$. After resuscitation, transfusion to hemoglobin $70-80 \mathrm{~g} / \mathrm{L}$, and correction of coagulopathy, endoscopy was undertaken. (B) Through-the-scope clips were applied after dilute epinephrine was injected into the four quadrants of the ulcer base. The fibrotic base made application of the clips problematic. (C) There was ongoing intermittent oozing of blood. Given the high risk ulcer, hemostatic powder spray was then applied to good effect. High dose intravenous proton pump inhibitors (PPIs) were given and the patient was managed in the hospital high dependency unit. Because of the clinical situation and the difficulty in providing endoscopic therapy to this large fibrotic ulcer, the plan for urgent referral for radiological embolization-should early rebleeding occur-was clearly documented by the endoscopist as a "rebleeding plan." (D) Fifteen hours later the patient rebled and became hemodynamically unstable. He was again resuscitated appropriately, after which an interventional radiologist performed coil embolization of the gastroduodenal artery. The patient had no further bleeding and was restarted on anticoagulants on day 3. When he was discharged from hospital a week later he was still taking oral PPIs twice daily, but when the 14 day course was finished, the dose was reduced to once daily.

of sclerosants such as absolute ethanol, thermal contact devices such as bipolar electrocoagulation probes or heater probes, and through-the-scope clips. ${ }^{528}$ RCT data supporting efficacy in ulcer bleeding are more limited for non-contact thermal devices such as argon plasma coagulation. ${ }^{28}$ Vascular ectasias may also be treated with thermal methods, commonly argon plasma coagulation; radiofrequency ablation is another thermal contact modality sometimes used for gastric antral vascular ectasia. $^{81}$

Endoscopic injection of epinephrine should not be used as a single modality treatment. Meta-analyses have reported lower rates of further bleeding with an alternative modality compared with epinephrine alone (relative risk $0.58,0.36$ to 0.93 ) and with epinephrine combined with a second modality versus epinephrine alone (relative risk $0.34,0.23$ to 0.50$).{ }^{82} 83$ Epinephrine can be used for temporary control of bleeding to aid visualization of the lesion before definitive treatment with another modality (such as a thermal or mechanical) or to decrease the risk of inducing bleeding with the application of a second modality.

Most data on non-variceal upper gastrointestinal bleeding are from patients with peptic ulcer bleeding. The Forrest classification of endoscopic stigmata is commonly used by endoscopists to identify higher risk lesions that require the application of endoscopic therapy.$^{84}$ Endoscopic therapy significantly decreases further bleeding and the need for urgent intervention in patients with ulcers with spurting or oozing blood (Forrest $1 \mathrm{a}$ or $1 \mathrm{~b}$ ) or with non-bleeding visible vessels (Forrest 2a; fig 4A). ${ }^{28}$ Patients with adherent clots (Forrest $2 b$ ) were not shown to benefit from endoscopic therapy in a meta-analysis of RCTs, but results of individual trials were very heterogeneous. ${ }^{80}$ This has led to guideline recommendations that either endoscopic plus medical therapy or medical management alone may be used for patients with adherent clots. ${ }^{528}$ Around $25-50 \%$ of patients admitted to hospital with bleeding ulcers have Forrest $1 \mathrm{a}, 1 \mathrm{~b}, 2 \mathrm{a}$, or $2 \mathrm{~b}$ stigmata. ${ }^{765}$ Endoscopic treatment is not needed for ulcers with flat pigmented spots or a clean base (Forrest $2 \mathrm{c}$ or $3) .^{528}$

\section{Variceal bleeding}

Variceal bleeding accounted for $11 \%$ of patients admitted to hospital with acute upper gastrointestinal bleeding in a nationwide UK audit. ${ }^{15}$ However, the proportion of patients with variceal bleeding varies widely and is related to the proportion of people with liver disease in the population served. Patients with variceal bleeding have a higher mortality than those with non-variceal bleeding, and this is largely related to the severity of underlying liver disease. ${ }^{1486}$

The optimal endoscopic therapy for esophageal variceal bleeding is variceal band ligation, which is associated with less rebleeding and fewer side effects than sclerotherapy. ${ }^{4987}$ If gastric varices are found, ligation can be used for gastroesophageal varices type-1, where esophageal varices extend several centimeters distally along the gastric lesser curve. Injection of tissue adhesive (eg, $\mathrm{N}$-butyl-cyanoacrylate) is the recommended endoscopic approach for all other types of gastric varices, although thrombin injection can be considered. ${ }^{7988-90}$ Thrombin injection has been described for gastric variceal bleeding in cohort studies, but to date no RCTs have compared it with other treatments. ${ }^{91-93}$

\section{Post-endoscopic management \\ PPI therapy}

A meta-analysis of RCTs comparing PPIs to placebo or no therapy in high risk patients undergoing successful endoscopic therapy showed that high dose PPIs, usually given as an intravenous bolus of $80 \mathrm{mg}$ followed by continuous infusion at $8 \mathrm{mg} / \mathrm{h}$ for 72 hours, reduced rebleeding (relative risk $0.40,0.28$ to 0.59$)$ and mortality $(0.41,0.20$ to 0.84 ). Intermittent intravenous or oral PPIs reduced rebleeding $(0.53,0.35$ to 0.78$)$ but not mortality. ${ }^{82} \mathrm{~A}$ 
meta-analysis of 13 studies found that a bolus followed by intermittent doses of intravenous or oral PPIs was noninferior to continuous infusion (further bleeding risk ratio 0.72; one sided $95 \%$ confidence interval upper boundary 0.97), although most individual studies were relatively small and not designed to answer this question. ${ }^{94}$ No conclusions could be made regarding oral versus intravenous dosing, ${ }^{94}$ although oral administration provides an antisecretory effect comparable to equivalent doses of intravenous PPIs. ${ }^{95}$ Guidelines have recommended an intravenous bolus followed by continuous infusion PPI therapy, ${ }^{35628}$ although recent guidelines also suggest considering intermittent high doses of oral or intravenous PPI (eg, 80-160 mg daily in divided doses after an initial 80 mg bolus), rather than continuous infusion. ${ }^{56}$

Patients with peptic ulcer bleeding generally receive four to eight weeks of once daily oral PPIs. Those with low risk endoscopic lesions (clean base, flat spot) should receive PPIs once a day from the time of diagnosis. Those with high risk endoscopic lesions and clinical features should receive high dose PPIs on days one to three as above, followed by twice daily oral PPI on days four to 14. This regimen is based on an RCT of 187 patients that showed significantly less rebleeding with twice daily versus once daily PPIs (relative risk $0.41,0.18$ to 0.93 ) during this period. ${ }^{96}$

The benefits of PPIs outweigh potential risks when used after bleeding from a peptic ulcer. Multiple pharmacodynamics studies report that omeprazole reduces the antiplatelet effect of clopidogrel, but a double blind placebo controlled trial in 3761 clopidogrel users found no evidence that omeprazole increased cardiovascular events (hazard ratio $0.99,0.68$ to 1.44$).{ }^{97}$ The US Food and Drug Administration recommends avoiding the use of omeprazole or esomeprazole in patients who are taking clopidogrel. $^{98}$

\section{Patients with cirrhosis and variceal bleeding}

As noted above, in patients with cirrhosis and upper gastrointestinal bleeding, antibiotics should be continued for up to seven days, ${ }^{7-9}$ regardless of whether varices are identified as the source of the bleeding. Patients who have documented variceal bleeding at endoscopy should also have their vasoactive drugs continued for up to five days. ${ }^{7-9}$ Combined treatment with endoscopic ligation and vasoactive drugs is superior to ligation alone or vasoactive drugs alone in reducing further bleeding in hospital or during the first seven days after treatment. ${ }^{99} 100$

Transjugular intrahepatic portosystemic shunt (TIPS) may also be used after initial endoscopic therapy in the first three days after presentation for the treatment of acute esophageal variceal bleeding in patients with Child-Pugh class C cirrhosis (score 10-13) ${ }^{89}$ A multicenter RCT compared early (within $72 \mathrm{~h}$ ) TIPS placement versus standard treatment with variceal ligation plus drug therapy in 63 patients with Child-Pugh C cirrhosis or Child-Pugh B cirrhosis with active bleeding. It reported that more patients were free from further bleeding at one year with early TIPS (97\% v 50\%; P<0.001). ${ }^{101}$ One year survival was also higher with early TIPS $(86 \% v 61 \%$; $\mathrm{P}<0.001)$ and encephalopathy was not increased. Subsequent reports suggest that the benefit is primarily in those with ChildPugh C disease. ${ }^{102}$ However the evidence for early TIPS remains relatively limited and the practicalities may be challenging for many units.

\section{Reintroduction of antithrombotic drugs}

Several studies suggest a survival benefit from continuing or reintroducing antithrombotic drugs after upper gastrointestinal bleeding. ${ }^{103} 104$ This is perhaps unsurprising given that mortality after presentation with a bleed is more often caused by underlying comorbidities, particularly cardiovascular disease, rather than the bleed itself. ${ }^{77}$ However, balancing the risks and benefits of reintroducing these drugs after a patient presents with upper gastrointestinal bleeding can be challenging. If an antithrombotic drug is reintroduced, a PPI is usually also administered.

Aspirin is the most widely studied antithrombotic drug in patients with upper gastrointestinal bleeding. Stratification of patients must be based on whether aspirin is given for secondary or primary cardiovascular prevention. This is because the benefit in secondary prevention is far greater than that for primary prevention, with a number needed to treat to prevent myocardial infarction, stroke, or vascular death of 67 versus $1745 .^{80}$

A randomized study of 156 patients with peptic ulcer bleeding who had been taking aspirin for secondary prevention reported reduced mortality at eight weeks in those who continued aspirin compared with those who discontinued the drug $(1.3 \% v 12.9 \%$; difference $11.6 \%$, $3.7 \%$ to $19.5 \%){ }^{103}$ Therefore, current guidelines suggest continuing aspirin (or reintroducing the drug within three days for higher risk endoscopic lesions) once hemostasis is achieved..$^{4-6105106}$ It has been suggested that when aspirin has been prescribed for primary prophylaxis, it should be stopped in most patients because the bleeding risk probably outweighs the cardiovascular benefit. ${ }^{28}$ If primary prevention is still clinically required after the bleed, it can be reintroduced after the ulcer has healed, or earlier depending on the clinical situation. ${ }^{5}$

No randomized studies are available to guide clinicians on the reintroduction of thienopyridines (eg, clopidogrel) or anticoagulants. Recent guidelines suggest that for patients receiving dual antiplatelet therapy, at least one drug, usually aspirin, should be reintroduced early as above, with the second drug withheld for up to five days after hemostasis, or the timing discussed with a cardiovascular specialist. ${ }^{56105}$

Similar to the situation with antiplatelet agents, observational studies in patients who develop upper gastrointestinal bleeding while taking warfarin indicate that those who restart warfarin have markedly lower rates of death and thromboembolic events, without a higher rate of recurrent bleeding, when compared with those whose warfarin is not restarted. ${ }^{104107}$ Recent guidelines suggest restarting warfarin from "as soon as hemostasis is established" 6 to seven to 15 days after the bleeding event. ${ }^{5}$ The indication for anticoagulation should be assessed at the time of the bleed, with early reintroduction (zero to seven days) recommended in patients with a higher thromboembolic risk. ${ }^{56}$ However, robust data on the optimal timing of reintroduction are not available. 
Data on the timing of the reintroduction of DOACs after bleeding has been controlled are limited, and this clearly depends on the balance of risk between rebleeding and thromboembolic events. Use of the CHA2DS2-VASC (Congestive heart failure, Hypertension, Age-2, Diabetes, Stroke/TIA-2, Vascular disease) and HAS-BLED (Hypertension, Abnormal renal and liver function, Stroke, prior Bleeding, Labile INRs, Elderly ( $>65$ years), Drugs and alcohol) scores may help in this situation. ${ }^{108-110}$ The recent Asia-Pacific guidelines suggest reintroducing DOACs in patients with a high thromboembolic risk as soon as hemostasis is achieved, although others have suggested that patients should have their anticoagulant restarted at day 7 , with possible bridging therapy with low molecular weight heparin from days 2 to 7 in those with a low bleeding risk. ${ }^{6}$ In general, patients with an increased thromboembolic risk should have early reintroduction of antithrombotic drugs, because the risks and severity of thromboembolic events generally outweigh those of bleeding events.

\section{Management of persistent or recurrent bleeding, including role of interventional radiology and surgery Non-variceal bleeding}

The results of an RCT comparing repeat endoscopic therapy with surgery in 92 patients with recurrent peptic ulcer bleeding indicate that endoscopic therapy should be repeated when bleeding recurs after initial endoscopic control. ${ }^{111}$ This study reported similar mortality, although more patients had complications with surgery $(36.4 \% \mathrm{v}$ $14.6 \% ; \mathrm{P}=0.03)$. For patients with persistent or refractory bleeding from non-variceal sources despite optimal standard endoscopic and medical therapy, the addition of hemostatic powder spray for temporary control (12-24 h) or over-the-scope clips (OTSC) as a rescue modality is suggested, in parallel with ongoing resuscitation..$^{56112113}$

For peptic ulcer bleeding not controlled by endoscopic therapy, two recent meta-analyses of observational studies that compared surgery with radiological intervention reported lower rebleeding with surgery, but similar mortality and need for further interventions, although patients receiving radiological intervention were older and in worse general health. ${ }^{114115}$ Because many patients with recurrent bleeding are elderly with comorbidities, interventional radiology is generally preferred if locally available. Therefore, if bleeding continues despite optimal endoscopic therapy, transarterial embolization is recommended, although surgery should be considered if radiological therapy is likely to be delayed. ${ }^{45}$

Prophylactic transarterial embolization of high risk ulcers after endoscopic therapy is not recommended: it did not significantly reduce rebleeding when compared with standard treatment $(10.2 \% v 11.4 \%)$ in an RCT of 241 patients. ${ }^{116}$

\section{Variceal bleeding}

Patients with rebleeding after initial endoscopic and medical therapy for varices may have repeat endoscopic therapy performed. ${ }^{8}$ TIPS is recommended for those with persistent or severe recurrent bleeding. ${ }^{7-9}$ For patients with severe bleeding refractory to endoscopic therapy, balloon tamponade has been recommended as a temporary bridge to definitive therapy. ${ }^{78}$ However, balloon tamponade is associated with serious complications (such as esophageal rupture and aspiration pneumonia) in about $12 \%$ of patients and its use was lethal in $6 \%$ of patients in a case series. ${ }^{117}$ Recently, removable self expanding covered metal esophageal stents designed for the treatment of severe esophageal variceal bleeding have become available (although they are not approved in the US). An RCT of 28 patients compared these stents with balloon tamponade in patients with esophageal variceal bleeding refractory to medical and endoscopic therapy and showed that the stents led to improved bleeding control (85\% v 47\%; Fisher's exact test $\mathrm{P}=0.055)$, with similar mortality. ${ }^{118}$

\section{Emerging treatments}

\section{Hemostatic powder spray}

Hemostatic powder spray provides high rates of initial hemostasis for active non-variceal upper gastrointestinal bleeding, but with relatively high rebleeding rates, suggesting a temporary effect. ${ }^{119-123}$ A systematic review of 195 cases reported initial hemostasis in $92 \%$ and a seven day rebleeding rate of $21 \% .{ }^{112}$ Currently, hemostatic powder is often used as a temporary rescue treatment for bleeding that cannot be controlled using established methods, and it may have a role for the initial control of diffuse bleeding from tumors. ${ }^{6112}$ More limited data are available on hemostatic powder spray for variceal bleeding, often as a temporizing method until definitive therapy is applied. ${ }^{124}$

\section{Over-the-scope clips}

Treatment with OTSC is another relatively new technique. These clips are much larger than standard through-thescope clips so may be successful when applied to larger fibrotic lesions or larger feeding vessels. A multicenter RCT of 66 patients with recurrent ulcer bleeding after initial hemostasis showed that significantly fewer patients treated with OTSC had further bleeding compared with those on standard therapy (15\% v 58\%; difference $42 \%$, $22 \%$ to $63 \%) .{ }^{125}$ Further data are awaited, but at present OTSC may be considered as a rescue therapy when standard therapies do not achieve permanent hemostasis.

\section{Doppler probes}

Endoscopic Doppler probes have also been studied as a guide to endoscopic therapy. A recent dual center RCT of 148 patients with severe non-variceal upper gastrointestinal bleeding that compared endoscopic therapy guided by Doppler probe positive signals with standard endoscopic therapy guided by endoscopic stigmata found reduced 30 day rebleeding with Doppler guided therapy (11.1\% v 26.3\%; $\mathrm{P}=0.02) .{ }^{126}$ Further data on the clinical utility and practicalities of this approach are needed, and currently the use of these probes is not recommended by guidelines. ${ }^{56}$

\section{Guidelines}

As already noted, international, UK (NICE), American, European, and Asia-Pacific guidelines on upper gastro- 


\begin{tabular}{|c|c|c|c|c|c|}
\hline \multicolumn{6}{|c|}{ Recommendations from major published guidelines on non-variceal UGIB } \\
\hline Guideline & Risk scoring & Prokinetics & Pre-endoscopy PPIs & Timing of endoscopy & Post-endoscopy PPIs \\
\hline $\begin{array}{l}\text { International, } \\
2010^{3}\end{array}$ & $\begin{array}{l}\text { Prognostic scales recommended to } \\
\text { identify high and low risk groups }\end{array}$ & $\begin{array}{l}\text { Promotility agents } \\
\text { should not be used } \\
\text { routinely }\end{array}$ & $\begin{array}{l}\text { May be considered but should not } \\
\text { delay endoscopy }\end{array}$ & Within $24 \mathrm{~h}$ for most patients & $\begin{array}{l}\text { IV PPI bolus then infusion if } \\
\text { high risk stigmata and have had } \\
\text { successful endoscopic therapy }\end{array}$ \\
\hline $\begin{array}{l}\text { US, ACG (ulcer } \\
\text { bleeding only) } \\
2012^{28}\end{array}$ & $\begin{array}{l}\text { Carry out risk assessment to stratify } \\
\text { into higher and lower risk groups. } \\
\text { Consider discharge from ED if GBS=0 }\end{array}$ & $\begin{array}{l}\text { Consider IV } \\
\text { erythromycin }\end{array}$ & IVPPIs may be considered & $\begin{array}{l}\text { Within } 24 \mathrm{~h} \text { after resuscitation. } \\
\text { Consider within } 12 \text { h if high risk } \\
\text { features (eg, hemodynamic instability, } \\
\text { bloody emesis in hospital) }\end{array}$ & $\begin{array}{l}\text { After successful endoscopic } \\
\text { hemostasis, give IV PPI bolus } \\
\text { then infusion to those with active } \\
\text { bleeding, NBV, or adherent clot }\end{array}$ \\
\hline $\begin{array}{l}\text { US, ASGE } \\
2012^{57}\end{array}$ & $\begin{array}{l}\text { No specific recommendation but } \\
\text { notes that GBS=0 identifies a very low } \\
\text { risk group }\end{array}$ & $\begin{array}{l}\text { Suggest IV prokinetic } \\
\text { if high probability of } \\
\text { fresh blood or clot in } \\
\text { stomach }\end{array}$ & IVPPIs recommended & $\begin{array}{l}\text { Depends on clinical factors but } \\
\text { recommends within } 24 \mathrm{~h} \text { in the } \\
\text { presence of cancer, cirrhosis, } \\
\text { hematemesis, hypovolemia, or } \mathrm{Hb} \\
<80 \mathrm{~g} / \mathrm{L}\end{array}$ & $\begin{array}{l}\text { IV PPI bolus then infusion after } \\
\text { endoscopic therapy for ulcers with } \\
\text { high risk stigmata }\end{array}$ \\
\hline UK, NICE $2012^{4}$ & $\begin{array}{l}\text { Use GBS before endoscopy and } \\
\text { full Rockall score after endoscopy. } \\
\text { Consider early discharge if GBS=0 }\end{array}$ & Notassessed & Do not give PPIs before endoscopy & $\begin{array}{l}\text { Within } 24 \mathrm{~h} \text {, but immediately after } \\
\text { resuscitation if unstable and severe } \\
\text { UGIB }\end{array}$ & $\begin{array}{l}\text { Offer PPIs if stigmata of recent } \\
\text { bleeding seen at endoscopy }\end{array}$ \\
\hline $\begin{array}{l}\text { Europe, ESGE } \\
2015^{5}\end{array}$ & $\begin{array}{l}\text { Patients with GBS 0-1 do not require } \\
\text { early endoscopy or admission }\end{array}$ & $\begin{array}{l}\text { Recommend IV } \\
\text { erythromycin if } \\
\text { clinically severe or } \\
\text { ongoing active UGIB }\end{array}$ & $\begin{array}{l}\text { IV bolus then infusion but should } \\
\text { not delay endoscopy }\end{array}$ & $\begin{array}{l}\text { Within } 24 \mathrm{~h} \text { of resuscitation, but } \\
\text { consider within } 12 \mathrm{~h} \text { if high risk } \\
\text { features (eg, hemodynamic instability } \\
\text { despite resuscitation, inpatient bloody } \\
\text { emesis, contraindication to stopping } \\
\text { anticoagulants) }\end{array}$ & $\begin{array}{l}\text { IV PPI bolus then } 72 \mathrm{~h} \text { infusion for } \\
\text { patients who receive endoscopic } \\
\text { hemostasis and those with } \\
\text { adherent clots. Consider giving } \\
\text { PPIs as intermittent IV bolus or } \\
\text { high dose oral }\end{array}$ \\
\hline $\begin{array}{l}\text { Asia-Pacific, } \\
2018^{6}\end{array}$ & $\begin{array}{l}\text { Use GBS; adopting a cut off at GBS } \\
\leq 1 \text { allows most hospitals to reduce } \\
\text { unnecessary admissions }\end{array}$ & Not assessed & $\begin{array}{l}\text { IV PPIs recommended if suspected } \\
\text { UGIB awaiting endoscopy } \\
\text { (especially if endoscopy is not } \\
\text { available within } 24 \mathrm{~h} \text { ) }\end{array}$ & $\begin{array}{l}\text { Within } 24 \mathrm{~h} \text {, but urgent (within } 12 \\
\text { h) if hemodynamic instability, after } \\
\text { resuscitation and stabilization }\end{array}$ & $\begin{array}{l}\text { After endoscopic hemostasis is } \\
\text { achieved high dose oral PPIs can } \\
\text { be used for } 72 \mathrm{~h} \text { as an alternative } \\
\text { to high dose IV PPIs }\end{array}$ \\
\hline
\end{tabular}

作 GBS=Glasgow Blatchford score; $\mathrm{Hb}=$ hemoglobin; NBVV=non-bleeding visible vessel; NICE=National Institute for Health and Care Excellence; PPIs=proton pump inhibitors; IV=intravenous; UGIB=upper gastrointestinal bleeding.

\section{QUESTIONS FOR FUTURE RESEARCH}

- What is the optimal approach to fluid resuscitation in patients with acute upper gastrointestinal bleeding?

- Can risk assessment tools be developed to allow accurate early identification of high risk patients with upper gastrointestinal bleeding, such as those who require endoscopic therapy or those with high mortality?

- What is the optimal timing of endoscopy after upper gastrointestinal bleeding?

-What is the exact role of hemostatic powder spray, over-the-scope clips, and Doppler ultrasound probes in the endoscopic management of upper gastrointestinal bleeding?

-When is the best time to reintroduce antithrombotic drugs after upper gastrointestinal bleeding?

intestinal bleeding (non-variceal and variceal) have been published over the past eight years. We have therefore referenced them as appropriate throughout. The most recent ones-the European (2015) and Asia-Pacific (2018) guidelines on non-variceal bleeding, and the UK, international, and US guidelines on variceal bleeding-differ slightly from earlier ones, largely because they assessed more recently published studies (table). These guidelines have generally been written by experts in this field, although methodology has varied.

\section{Conclusions}

Upper gastrointestinal bleeding remains a common cause of presentation to hospitals worldwide, and many recent studies have assessed the management of patients with this condition. The evidence of improved outcomes from a relatively restrictive approach to blood transfusion and the ability to identify patients who are at very low risk and suitable for outpatient management have recently altered clinical practice, and these alterations to management are now recommended by international guidelines. RCTs and meta-analyses confirm a benefit from pre-endoscopy antibiotics and vasoactive drugs in patients with cirrhosis, and post-endoscopy high dose PPIs for high risk peptic ulcer bleeding.

Endoscopic therapy has advanced dramatically over the past decades, with recent additions to the endoscopist's "toolkit," including hemostatic powder spray, over-thescope clips, and Doppler probes. These join the established and widely studied injection therapies, thermal probes, and clips used for non-variceal bleeding, and endoscopic band ligation and tissue adhesive injection for variceal bleeding. However, the newer modalities require further study to clarify their exact role in endoscopic management. Technical improvements and more widely available services for interventional radiology have led to it being the most commonly used rescue therapy for persistent or recurrent upper gastrointestinal bleeding that is refractory to endoscopic treatment. Surgery is now typically reserved for situations in which interventional radiology is unavailable, delayed, or unsuccessful.

The more widespread use of antiplatelet and anticoagulants drugs has led to uncertainty in managing patients taking these medications who develop upper gastrointestinal bleeding. However, recent data suggest that relatively early reintroduction of these drugs once hemostasis has been achieved is the best approach in those with appropriate cardiovascular indications. New approaches under investigation for managing upper gastrointestinal bleeding include the early use of TXA and novel endoscopic techniques to reduce rebleeding. These and other developments will hopefully continue to improve management and outcomes for patients with upper gastrointestinal bleeding. 


\section{HOW PATIENTS WERE INVOLVED IN THE CREATION OF THIS ARTICLE}

After email communication from the UK Gastroenterology Charity "Guts-UK" (previously CORE) to their members and related charities, three patients kindly volunteered to review the manuscript. In response to their comments, the sections on blood transfusion and timing of endoscopy were revised.

Thanks to Deepak Vishwanath for help with the radiological image in fig 4. Contributors: Both authors contributed equally to the planning and writing of the article and both are responsible for the overall content as guarantors. Competing interests: We have read and understood BMJ policy on declaration of interests and declare the following interests: AJS, none; LL has had single consultancies to Takeda and to Bayer and his full competing interests are available from her on request.

1 Laine L, Laursen SB, Zakko L, et al. Severity and outcomes of upper gastrointestinal bleeding with bloody vs coffee-grounds hematemesis. Am J Gastroenterol 2018;113:358-66. 10.1038 ajg.2018.5. pmid:29380820.

2 Lanas A. Editorial: Upper GI bleeding-associated mortality: challenges to improving a resistant outcome. Am I Gastroenterol 2010;105:90-2. 10.1038/ajg.2009.517 pmid:20054306.

3 Barkun AN, Bardou M, Kuipers EJ, et al. International Consensus Uppe Gastrointestinal Bleeding Conference Group. International consensus recommendations on the management of patients with nonvariceal upper gastrointestinal bleeding. Ann Intern Med 2010:152:101-13. 10.7326/0003-4819-152-2-201001190-00009 pmid:20083829.

4 National Institute for Health and Care Excellence. Acute upper gastrointestinal bleeding in over 16s: management. CG141. 2012. https:// www.nice.org.uk/guidance/cg141.

5 Gralnek IM, Dumonceau IM, Kuipers El, et al. Diagnosis and management of nonvariceal upper gastrointestinal hemorrhage: European Society of Gastrointestinal Endoscopy (ESGE) Guideline. Endoscopy 2015;47:a1-46. 10.1055/s-0034-1393172 pmid:26417980

6 Sung JJ, Chiu PW, Chan FKL, et al. Asia-Pacific working group consensus on non-variceal upper gastrointestinal bleeding: an update 2018. Gut 2018:67-1757-68.10.1136/gutinl-2018-316276. pmid-29691276.

Tripathi D, Stanley AJ, Hayes PC, et al. Clinical Services and Standards Committee of the British Society of Gastroenterology. U.K. guidelines on the management of variceal haemorrhage in cirrhotic patients. Gut 2015;64:1680-704. 10.1136/gutjnl-2015-309262 pmid:25887380.

8 de Franchis R. Baveno VI Faculty. Expanding consensus in portal hypertension: report of the Baveno VI Consensus Workshop: Stratifying risk and individualizing care for portal hypertension. J Hepatol 2015;63:74352.10.1016/j.jhep.2015.05.022 pmid:26047908.

9 Garcia-Tsao G, Abraldes JG, Berzigotti A, Bosch J. Portal hypertensive bleeding in cirrhosis: Risk stratification, diagnosis, and management: 2016 practice guidance by the American Association for the study of liver diseases. Hepatology 2017;65:310-35. 10.1002/hep.28906 pmid:27786365.

10 Rockall TA, Logan RFA, Devlin HB, Northfield TC. Incidence of and mortality from acute upper gastrointestinal haemorrhage in the UK. BMJ 1995:311:222-6. 10.1136/bmi.311.6999.222 pmid:7627034.

11 Blatchford O, Davidson LA, Murray WR, Blatchford M, Pelll. Acute upper gastrointestinal haemorrhage in west of Scotland: case ascertainment study. BMJ 1997;315:510-4. 10.1136/ bmj.315.7107.510 pmid:9329304

12 Laine L, Yang H, Chang SC, Datto C. Trends for incidence of hospitalization and death due to GI complications in the United States from 2001 to 2009. Am J Gastroenterol 2012;107:1190-5, quiz 1196. 10.1038/ ajg.2012.168 pmid:22688850

13 Abougergi MS, Travis AC, Saltzman JR. The in-hospital mortality rate for upper $\mathrm{GI}$ hemorrhage has decreased over 2 decades in the United States: a nationwide analysis. Gastrointest Endosc 2015;81:882-8.e1.10.1016/i. gie.2014.09.027 pmid:25484324.

14 Wuerth BA, Rockey DC. Changing epidemiology of upper gastrointestinal hemorrhage in the last decade: a nationwide analysis. Dig Dis SCi 2018;63:1286-93. 10.1007/s10620-017-4882-6 pmid:29282637.

15 Hearnshaw SA, Logan RFA, Lowe D, Travis SP, Murphy MF, Palmer KR Acute upper gastrointestinal bleeding in the UK: patient characteristics, diagnoses and outcomes in the 2007 UK audit. Gut 2011;60:1327-35. 10.1136/ gut.2010.228437 pmid:21490373.

16 Nahon S, Hagège H, Latrive JP, et al. Groupe des Hémorragies Digestives Hautes de l'ANGH. Epidemiological and prognostic factors involved in upper gastrointestinal bleeding: results of a French prospective multicenter study. Endoscopy 2012;44:998-1008. 10.1055/s-00321310006 pmid:23108771.

17 Bickell WH, Wall MJ Jr, Pepe PE, et al. Immediate versus delayed fluid resuscitation for hypotensive patients with penetrating torso injuries. N EnglJ Med 1994;331:1105-9. 10.1056/ NEIM199410273311701 pmid.7935634

18 Carrick MM, Morrison CA, Tapia NM, et al. Intraoperative hypotensive resuscitation for patients undergoing laparotomy or thoracotomy for trauma: Early termination of a randomized prospective clinical trial. J Trauma Acute Care Surg 2016;80:886-96. 10.1097/ TA.0000000000001044 pmid:27015578
19 Perel P, Roberts I, Ker K. Colloids versus crystalloids for fluid resuscitation in critically ill patients. Cochrane Database Syst Rev 2013;28:CD000567 .pmid:23450531.

20 Semler MW, Self WH, Wanderer IP, et al. SMART Investigators and the Pragmatic Critical Care Research Group. Balanced crystalloids versus saline in critically ill adults. N Engl / Med 2018;378:829-39. 10.1056/ NEJMoa1711584 pmid:29485925.

21 Carson JL, Stanworth SJ, Roubinian N, et al. Transfusion thresholds and other strategies for guiding allogeneic red blood cell transfusion. Cochrane Database Syst Rev 2016:10:CD002042 pmid.27731885.

22 Carson JL, Guyatt G, Heddle NM, et al. Clinical practice guidelines from the AABB: red blood cell transfusion thresholds and storage. JAMA 2016;316:2025-35.10.1001/jama.2016.9185 pmid:27732721.

23 Docherty AB, O'Donnell R, Brunskill S, et al. Effect of restrictive versus liberal transfusion strategies on outcomes in patients with cardiovascular disease in a non-cardiac surgery setting: systematic review and metaanalysis. BMJ 2016;352:i1351. 10.1136/bmj.i1351 pmid:27026510.

24 Blair SD, Janvrin SB, McCollum CN, Greenhalgh RM. Effect of early blood transfusion on gastrointestinal haemorrhage. Br / Surg 1986;73:783-5. 10.1002/bjs.1800731007 pmid:3533203

25 Villanueva C, Colomo A, Bosch A, et al. Transfusion strategies for acute upper gastrointestinal bleeding. N Engl J Med 2013;368:11-21. 10.1056/NEJMoa1211801 pmid:23281973.

26 Jairath V, Kahan BC, Gray A, et al. Restrictive versus liberal blood transfusion for acute upper gastrointestinal bleeding (TRIGGER) a pragmatic, open-label, cluster randomised feasibility trial. Lancet 2015;386:137-44. 10.1016/S0140-6736(14)619991 pmid:25956718

27 Odutayo A, Desborough MJ, Trivella M, et al. Restrictive versus liberal blood transfusion for gastrointestinal bleeding: a systematic review and meta-analysis of randomised controlled trials. Lancet Gastroenterol Hepatol 2017;2:354-60. 10.1016/S2468-1253(17)300547. pmid:28397699.

28 Laine L, Jensen DM. Management of patients with ulcer bleeding. Am J Gastroenterol 2012;107:345-60, quiz 361.10.1038/ ajg.2011.480 pmid:22310222.

29 Rockall TA, Logan RF, Devlin HB, Northfield TC. Risk assessment after acut upper gastrointestinal haemorrhage. Gut 1996;38:316-21.10.1136/ gut.38.3.316 pmid:8675081

30 Saeed ZA, Winchester CB, Michaletz PA, Woods KL, Graham DY. A scoring system to predict rebleeding after endoscopic therapy of nonvariceal upper gastrointestinal hemorrhage, with a comparison of heat probe and ethanol injection. Am J Gastroenterol 1993;88:1842-9.pmid:8237930.

31 Hay JA, Maldonado L, Weingarten SR, Ellrodt AG. Prospective evaluation of a clinical guideline recommending hospital length of stay in upper gastrointestinal tract hemorrhage. JAMA 1997;278:2151-6.10.1001/ jama 1997.03550240041031 pmid.9417008.

32 Blatchford O, Murray WR, Blatchford M. A risk score to predict need for treatment for upper-gastrointestinal haemorrhage. Lancet 2000;356:1318 21.10.1016/S0140-6736(00)02816-6 pmid:11073021.

33 Marmo R, Koch M, Cipolletta L, et al. Italian registry on upper gastrointestinal bleeding (Progetto Nazionale Emorragie Digestive--PNED 2). Predicting mortality in non-variceal upper gastrointestinal bleeders: validation of the Italian PNED Score and Prospective Comparison with the Rockall Score. Am J Gastroenterol 2010;105:1284-91.10.1038/ ajg.2009.687 pmid:20051943.

34 Saltzman IR, Tabak YP, Hyett BH, Sun X. Travis AC, Johannes RS. A simple risk score accurately predicts in-hospital mortality, length of stay, and cost in acute upper GI bleeding. Gastrointest Endosc 2011;74:1215-24 10.1016/j.gie.2011.06.024 pmid:21907980.

35 Stanley AJ, Laine L, Dalton HR, et al. International Gastrointestinal Bleeding Consortium. Comparison of risk scoring systems for patients presenting with upper gastrointestinal bleeding: international multicentre prospective study. BM/ 2017:356:16432. 10.1136/bmi. i6432 pmid:28053181

36 Laursen SB, Hansen JM, Schaffalitzky de Muckadell OB. The Glasgow Blatchford score is the most accurate assessment of patients with upper gastrointestinal hemorrhage. Clin Gastroenterol Hepatol 2012;10:1130 1135.e1. 10.1016/i.cgh.2012.06.022 pmid:22801061.

37 Yang HM, Jeon SW, Jung JT, et al. Daegu-Gyeongbuk Gastrointestinal Study Group (DGSG). Comparison of scoring systems for nonvariceal upper gastrointestinal bleeding: a multicenter prospective cohort study. J Gastroenterol Hepatol 2016;31:119-25. 10.1111/ jgh.13057 pmid:26211939.

38 Stanley AJ, Ashley D, Dalton HR, et al. Outpatient management of patients with low-risk upper-gastrointestinal haemorrhage: multicentre validation and prospective evaluation. Lancet 2009;373:42-7. 10.1016/S01406736(08)61769-9 pmid:19091393.

39 Ramaekers R, Mukarram M, Smith CA, Thiruganasambandamoorthy V. The predictive value of preendoscopic risk scores to predict adverse outcomes in emergency department patients with upper gastrointestinal bleeding: a systematic review. Acad Emerg Med 2016;23:1218-27. 10.1111 acem.13101 pmid:27640399.

40 Laursen SB, Dalton HR, Murray IA, et al. Upper Gastrointestinal Hemorrhage International Consortium Upper Gastrointestinal Hemorrhage International Consortium. Performance of new thresholds of the Glasgow Blatchford score in managing patients with upper gastrointestinal bleeding. Clin Gastroenterol Hepatol 2015;13:115-21 e2.10.1016/j.cgh.2014.07.023 pmid:25058843. 
41 Dunne PDJ, Laursen SB, Laine L, et al. Previous use of antithrombotic agents reduces mortality and length of hospital stay in patients with high-risk upper gastrointestinal bleeding. Clin Gastroenterol Hepatol 2019;17:440-447.e2.10.1016/j.cgh.2018.04.046. pmid:29705263.

42 Chang HY, Zhou M, Tang W, Alexander GC, Singh S. Risk of gastrointestina bleeding associated with oral anticoagulants: population based retrospective cohort study. BM/ 2015;350:h1585. 10.1136/bmj. h1585 pmid:25911526.

43 Huang ES, Strate LL, Ho WW, Lee SS, Chan AT. Long-term use of aspirin and the risk of gastrointestinal bleeding. Am J Med 2011;124:426-33. 10.1016/j.amjmed.2010.12.022 pmid:21531232.

44 Ahsberg K, Höglund P, Kim WH, von Holstein CS. Impact of aspirin, NSAIDS, warfarin, corticosteroids and SSRIs on the site and outcome of non-variceal upper and lower gastrointestinal bleeding. Scand I Gastroenterol 2010;45:1404-15. 10.3109/00365521.2010.510567 pmid:20695720.

45 Acosta RD, Abraham NS, Chandrasekhara V, et al. ASGE Standards of Practice Committee. The management of antithrombotic agents for patients undergoing Gl endoscopy. Gastrointest Endosc 2016;83:3-16. 10.1016/j.gie.2015.09.035 pmid:26621548

46 Zakko L, Rustagi T, Douglas M, Laine L. No benefit from platelet transfusion for gastrointestinal bleeding in patients taking antiplatelet agents. Clin Gastroenterol Hepatol 2017;15:46-52. 10.1016/j. cgh.2016.07.017 pmid:27464591.

47 Razzaghi A, Barkun AN. Platelet transfusion threshold in patients with upper gastrointestinal bleeding: a systematic review. J Clin Gastroenterol 2012;46:482-6. 10.1097/ MCG.0b013e31823d33e3 pmid:22688143.

48 Choudari CP, Rajgopal C, Palmer KR. Acute gastrointestinal haemorrhage in anticoagulated patients: diagnoses and response to endoscopic treatment. Gut 1994;35:464-6. 10.1136/gut.35.4.464 pmid:8174982.

49 Wolf AT, Wasan SK, Saltzman JR. Impact of anticoagulation on rebleeding following endoscopic therapy for nonvariceal upper gastrointestinal hemorrhage. Am J Gastroenterol 2007;102:290-6. 10.1111/j.1572 0241.2006.00969.x pmid:17100959.

50 Shingina A, Barkun AN, Razzaghi A, Martel M, Bardou M, Gralnek I. RUGBE Investigators. Systematic review: the presenting international normalised ratio (INR) as a predictor of outcome in patients with upper nonvariceal gastrointestinal bleeding. Aliment Pharmacol Ther 2011;33:1010-8. 10.1111/j.1365-2036.2011.04618.x pmid:21385193.

51 Veitch AM, Vanbiervliet G, Gershlick AH, et al. Endoscopy in patients on antiplatelet or anticoagulant therapy, including direct oral anticoagulants: British Society of Gastroenterology (BSG) and European Society of Gastrointestinal Endoscopy (ESGE) guidelines. Gut 2016;65:374-89. 10.1136/gutjnl-2015-311110 pmid:26873868.

52 Pollack CV Ir, Reilly PA, van Ryn I, et al. Idarucizumab for dabigatran reversal-full cohort analysis. N Engl J Med 2017;377:431-41. 10.1056/ NEJMoa1707278 pmid:28693366.

53 Connolly SJ, Milling TJ Jr, , Eikelboom JW, et al. ANNEXA-4 Investigators. Andexanet alfa for acute major bleeding associated with factor Xa inhibitors. NEngl/ Med 2016;375:1131-41. 10.1056/ NEIMoa1607887 pmid:27573206

54 Tripodi A, Mannucci PM. The coagulopathy of chronic liver disease. N Eng J Med 2011;365:147-56. 10.1056/NEJMra1011170 pmid:21751907.

55 Tripodi A, Primignani M, Chantarangkul V, et al. Thrombin generation in patients with cirrhosis: the role of platelets. Hepatology 2006;44:440-5. 10.1002/hep. 21266 pmid:16871542.

56 Sreedharan A, Martin J, Leontiadis Gl, et al. Proton pump inhibitor treatment initiated prior to endoscopic diagnosis in upper gastrointestinal bleeding. Cochrane Database Syst Rev 2010;7:CD005415.pm id:20614440.

57 Hwang JH, Fisher DA, Ben-Menachem T, et al Standards of Practice Committee of the American Society for Gastrointestinal Endoscopy. The role of endoscopy in the management of acute non-variceal upper GI bleeding. Gastrointest Endosc 2012;75:1132-8.10.1016/j. gie.2012.02.033 pmid:22624808

58 Rahman R, Nguyen DL, Sohail U, et al. Pre-endoscopic erythromycin administration in upper gastrointestinal bleeding: an updated metaanalysis and systematic review. Ann Gastroenterol 2016;29:312 7.pmid: 27366031

59 Gluud LL, Klingenberg SL, Langholz E. Tranexamic acid for upper gastrointestinal bleeding. Cochrane Database Syst Rev 2012;1:CD00664 0.pmid:22258969.

60 Gayet-Ageron A, Prieto-

Merino D, Ker K, Shakur H, Ageron FX, Roberts I. Antifibrinolytic Trials Collaboration. Effect of treatment delay on the effectiveness and safety of antifibrinolytics in acute severe haemorrhage: a meta-analysis of individual patient-level data from 40138 bleeding patients. Lancet 2018:391:125-32 10.1016/S0140-6736(17)324558. pmid: 29126600

61 Roberts I, Coats T, Edwards P, et al. HALT-IT--tranexamic acid for the treatment of gastrointestinal bleeding: study protocol for a randomised controlled trial. Trials 2014;15:450. 10.1186/1745-6215-15450. pmid: 25409738

62 Seo YS, Park SY, Kim MY, et al. Lack of difference among terlipressin, somatostatin, and octreotide in the control of acute gastroesophageal variceal hemorrhage. Hepatology 2014;60:954-63.10.1002 hep. 27006 pmid: 24415445 .
63 Levacher S, Letoumelin P, Pateron D, Blaise M, Lapandry C, Pourriat JL. Early administration of terlipressin plus glyceryl trinitrate to control active upper gastrointestinal bleeding in cirrhotic patients. Lancet 1995;346:865-8. 10.1016/S0140-6736(95)927085 pmid: 7564670

64 Avgerinos A, Nevens F, Raptis S, Fevery J. Early administration of somatostatin and efficacy of sclerotherapy in acute oesophageal variceal bleeds: the European Acute Bleeding Oesophageal Variceal Episodes (ABOVE) randomised trial. Lancet 1997;350:1495-9. 10.1016/S01406736(97)05099-X pmid:9388396.

65 Calès P, Masliah C, Bernard B, et al. French Club for the Study of Portal Hypertension. Early administration of vapreotide for variceal bleeding in patients with cirrhosis. N Engl J Med 2001;344:23-8. 10.1056/ NEJM200101043440104 pmid:11136956.

66 Avgerinos A, Sgouros S, Viazis N, et al. Somatostatin inhibits gastric acid secretion more effectively than pantoprazole in patients with peptic ulcer bleeding: a prospective, randomized, placebo-controlled trial. Scand J Gastroenterol 2005;40:515-22 10.1080/00365520510015458 pmid:16036503.

67 Whitehouse I, Beglinger C, Fried M, Gyr K. The effect of an octapeptide somatostatin analogue (SMS 201-995) and somatostatin-14 (SST-14) on pentagastrin-stimulated gastric acid secretion: a comparative study in man. Hepatogastroenterology 1984;31:227-9.pmid:6150888.

68 Chavez-Tapia NC, Barrientos-Gutierrez T, Tellez-Avila F, et al. Meta-analysis: antibiotic prophylaxis for cirrhotic patients with upper gastrointestinal bleeding-an updated Cochrane review. Aliment Pharmacol Ther 2011;34:509-18.10.1111/j.13652036.2011.04746.x pmid:21707680

69 Fernández J, Ruiz del Arbol L, Gómez C, et al. Norfloxacin vs ceftriaxone in the prophylaxis of infections in patients with advanced cirrhosis and hemorrhage. Gastroenterology 2006:131:1049-56, quiz 1285 . 10.1053/j.gastro.2006.07.010 pmid:17030175.

70 Strate LL, Gralnek IM. ACG clinical guideline: management of patients with acute lower gastrointestinal bleeding. Am J Gastroenterol 2016;111:459 74. 10.1038/ajg.2016.41. pmid:26925883.

71 Pasha SF, Shergill A, Acosta RD, et al. ASGE Standards of Practice Committee. The role of endoscopy in the patient with lower $G$ bleeding. Gastrointest Endosc 2014;79:875-85.10.1016/j. gie.2013.10.039 pmid:24703084.

72 Nadler M, Eliakim R. The role of capsule endoscopy in acute gastrointestinal bleeding. Therap Adv Gastroenterol 2014;7:87-92. $10.1177 / 1756283 \times 13504727$ pmid.24587821.

73 Lim LG, Ho KY, Chan YH, et al. Urgent endoscopy is associated with lower mortality in high-risk but not low-risk nonvariceal upper gastrointestinal bleeding. Endoscopy 2011;43:300-6. 10.1055/s-00301256110 pmid:21360421.

74 Cho SH, Lee YS, Kim YJ, et al. Outcomes and role of urgent endoscopy in high-risk patients with acute nonvariceal gastrointestinal bleeding. Clin Gastroenterol Hepatol 2018;16:370-7. 10.1016/j. cgh.2017.06.029 pmid:28634135

75 Lin HJ, Wang K, Perng CL, et al. Early or delayed endoscopy for patients with peptic ulcer bleeding. A prospective randomized study. J Clin Gastroenterol 1996:22:267-71.10.1097/00004836-19960600000005 pmid:8771420.

76 Laursen SB, Leontiadis GI, Stanley AJ, Møller MH, Hansen JM, Schaffalitzky de Muckadell OB. Relationship between timing of endoscopy and mortality in patients with peptic ulcer bleeding: a nationwide cohort study. Gastrointest Endosc 2017;85:936-944.e3. 10.1016/. gie.2016.08.049 pmid:27623102.

77 Sung JJ, Tsoi KK, Ma TK, Yung MY, Lau JY, Chiu PW. Causes of mortality in patients with peptic ulcer bleeding: a prospective cohort study of 10,428 cases. Am J Gastroenterol 2010;105:84-9. 10.1038/ ajg.2009.507 pmid:19755976.

78 Lee JG, Turnipseed S, Romano PS, et al. Endoscopy-based triage significantly reduces hospitalization rates and costs of treating upper $\mathrm{GI}$ bleeding: a randomized controlled trial. Gastrointest Endosc 1999;50:755-61.10.1016/S0016-5107(99)70154 9 pmid:10570332

79 Bjorkman DJ, Zaman A, Fennerty MB, Lieberman D, Disario JA, GuestWarnick G. Urgent vs. elective endoscopy for acute non-variceal upper-GI bleeding: an effectiveness study. Gastrointest Endosc 2004;60:1-8. 10.1016/S0016-5107(04)01287-8 pmid:15229417.

80 Laine L. Upper gastrointestinal bleeding due to a peptic ulcer. N Engl I Med 2016:374:2367-76. 10.1056/NEJMcp1514257 pmid:27305194.

81 Maida M, Camilleri S, Manganaro M, Garufi S, Scarpulla G. Radiofrequency ablation for treatment of refractory gastric antral vascular ectasia: a systematic review of the literature. Gastroenterol Res Pract 2017;2017:5609647. 10.1155/2017/5609647 pmid:28835751.

82 Laine L, McQuaid KR. Endoscopic therapy for bleeding ulcers: an evidence-based approach based on meta-analyses of randomized controlled trials. Clin Gastroenterol Hepatol 2009;7:33-47, quiz 1-2. 10.1016/j.cgh.2008.08.016 pmid:18986845

83 Vergara M, Bennett C, Calvet X, Gisbert JP. Epinephrine injection versus epinephrine injection and a second endoscopic method in high-risk bleeding ulcers. Cochrane Database Syst Rev 2014:10:CD005584.pm id:25308912

84 Forrest JA, Finlayson ND, Shearman DJ. Endoscopy in gastrointestinal bleeding. Lancet 1974;2:394-7. 10.1016/S0140$6736(74) 91770-X$ pmid:4136718. 
85 Enestvedt BK, Gralnek IM, Mattek N, Lieberman DA, Eisen G. An evaluation of endoscopic indications and findings related to nonvariceal upper-GI hemorrhage in a large multicenter consortium. Gastrointest Endosc 2008;67:422-9.10.1016/j.gie.2007.09.024 pmid:18206878.

86 Jairath V, Rehal S, Logan R, et al. Acute variceal haemorrhage in the United Kingdom: patient characteristics, management and outcomes in a nationwide audit. Dig Liver Dis 2014;46:419-26. 10.1016/i. dld.2013.12.010 pmid:24433997.

87 Laine L, Cook D. Endoscopic ligation compared with sclerotherapy for treatment of esophageal variceal bleeding. A meta-analysis. Ann Intern Med 1995;123:280-7. 10.7326/0003-4819-123-4-19950815000007 pmid:7611595

88 Lo GH, Lai KH, Cheng JS, Chen MH, Chiang HT. A prospective, randomized trial of butyl cyanoacrylate injection versus band ligation in the management of bleeding gastric varices. Hepatology 2001;33:1060-4. 10.1053/ jhep.2001.24116 pmid:11343232.

89 Tan PC, Hou MC, Lin HC, et al. A randomized trial of endoscopic treatment of acute gastric variceal hemorrhage: $\mathrm{N}$-butyl-2-cyanoacrylate injection versus band ligation. Hepatology 2006:43:690-7.10.1002/ hep. 21145 pmid: 16557539

90 Cheng LF, Wang ZQ, Li CZ, Lin W, Yeo AE, Jin B. Low incidence of complications from endoscopic gastric variceal obturation with butyl cyanoacrylate. Clin Gastroenterol Hepatol 2010;8:760-6.10.1016/j. cgh.2010.05.019 pmid:20621678.

91 Ramesh J, Limdi JK, Sharma V, Makin Al. The use of thrombin injections in the management of bleeding gastric varices: a single-center experience. GastrointestEndosc 2008;68:877-82.10.1016/. gie.2008.02.065 pmid:18534583

92 McAvoy NC, Plevris JN, Hayes PC. Human thrombin for the treatment of gastric and ectopic varices. World J Gastroenterol 2012;18:5912-7. 10.3748/wig. v18.i41.5912 pmid:23139607.

93 Smith MR, Tidswell R, Tripathi D. Outcomes of endoscopic human thrombin injection in the management of gastric varices. Eur / Gastroenterol Hepatol 2014;26:846-52. 10.1097/MEG.0000000000000119 pmid:24892515.

94 Sachar H, Vaidya K, Laine L. Intermittent vs continuous proton pump inhibitor therapy for high-risk bleeding ulcers: a systematic review and meta-analysis. JAMA Intern Med 2014;174:1755-62. 10.1001/ jamainternmed.2014.4056 pmid:25201154

95 Freston JW, Pilmer BL, Chiu YL, et al. Evaluation of the pharmacokinetics and pharmacodynamics of intravenous lansoprazole. Aliment Pharmacol Ther 2004:19:1111-22.10.1111/j.13652036.2004.01942.x pmid:15142201.

96 Cheng HC, Wu CT, Chang WL, Cheng WC, Chen WY, Sheu BS. Double oral esomeprazole after a 3-day intravenous esomeprazole infusion reduces recurrent peptic ulcer bleeding in high-risk patients: $\mathrm{a}$ randomised controlled study. Gut 2014:63:1864-72.10.1136/ gutjnl-2013-306531 pmid:24658598.

97 Bhatt DL, Cryer BL, Contant CF, et al. COGENT Investigators. Clopidogre with or without omeprazole in coronary artery disease. N Engl J Med 2010;363:1909-17.10.1056/NE)Moa1007964 pmid:20925534.

98 Sanofi; Bristol-Myers Squibb. Plavix. Highlights of prescribing information. 2018. https://www.accessdata.fda.gov/drugsatfda_docs/ label/2018/020839s069lbl.pdf

99 Lo GH, Chen WC, Wang HM, et al. Low-dose terlipressin plus banding ligation versus low-dose terlipressin alone in the prevention of very early rebleeding of oesophageal varices. Gut 2009;58:1275-80.10.1136/ gut.2008.165910 pmid:19386609.

100 Sung JJ, Chung SC, Yung MY, et al. Prospective randomised study of effect of octreotide on rebleeding from oesophageal varices after endoscopic ligation. Lancet 1995;346:1666-9. 10.1016/S0140-6736(95)928405 pmid:8551824.

101 García-Pagán JC, Caca K Bureau C etal Early TIPS (Transjugular Intrahepatic Portosystemic Shunt) Cooperative Study Group. Early use of TIPS in patients with cirrhosis and variceal bleeding. N Engl J Med 2010;362:2370-9. 10.1056/NEJMoa0910102 pmid:20573925.

102 Conejo I, Guardascione MA, Tandon P, et al. Multicenter external validation of risk stratification criteria for patients with variceal bleeding Clin Gastroenterol Hepatol 2018;16:132-139.e8. 10.1016/j. cgh.2017.04.042 pmid:28501536.

103 Sung JJ, Lau JY, Ching JY, et al. Continuation of low-dose aspirin therapy in peptic ulcer bleeding: a randomized trial. Ann Intern Med 2010;152:1-9. 10.7326/0003-4819-152-1-201001050-00179 pmid:19949136.

104 Qureshi W, Mittal C, Patsias I, et al. Restarting anticoagulation and outcomes after major gastrointestinal bleeding in atrial fibrillation. Am J Cardiol 2014;113:662-8. 10.1016/j.amjcard.2013.10.044 pmid:24355310.

105 Chan FKL, Goh KL, Reddy N, et al. Management of patients on antithrombotic agents undergoing emergency and elective endoscopy: joint Asian Pacific Association of Gastroenterology (APAGE) and Asian Pacific Society for Digestive Endoscopy (APSDE) practice guidelines. Gut 2018;67:405-17. 10.1136/gutjnl-2017-315131 pmid:29331946.

106 Scott MJ, Veitch A, Thachil J. Reintroduction of anti-thrombotic therapy after a gastrointestinal haemorrhage: if and when?BrJ Haematol 2017;177:185-97. 10.1111/bjh.14599. pmid:28272736.
107 Witt DM, Delate T, Garcia DA, et al. Risk of thromboembolism, recurrent hemorrhage, and death after warfarin therapy interruption for gastrointestinal tract bleeding. Arch Intern Med 2012;172:1484-91. 10.1001/archinternmed.2012.4261 pmid:22987143.

108 Gage BF, Waterman AD, Shannon W, Boechler M, Rich MW, Radford MJ. Validation of clinical classification schemes for predicting stroke: results from the National Registry of Atrial Fibrillation. JAMA 2001;285:2864-70. 10.1001/jama.285.22.2864 pmid:11401607.

109 Lip GY, Frison L, Halperin JL, Lane DA. Comparative validation of a novel risk score for predicting bleeding risk in anticoagulated patients with atrial fibrillation: the HAS-BLED (Hypertension, Abnormal Renal/Live Function, Stroke, Bleeding History or Predisposition, Labile INR, Elderly, Drugs/Alcohol Concomitantly) score. J Am Coll Cardiol 2011;57:173-80. 10.1016/j.jacc.2010.09.024 pmid:21111555.

110 Zulkifly H, Lip GYH, Lane DA. Bleeding risk scores in atrial fibrillation and venous thromboembolism. Am J Cardiol 2017;120:1139-45. 10.1016/j. amjcard.2017.06.058 pmid:28800833.

111 Lau JYW, Sung JJY, Lam YH, et al. Endoscopic retreatment compared with surgery in patients with recurrent bleeding after initial endoscopic control of bleeding ulcers. N Engl J Med 1999;340:751-6. 10.1056 NEIM199903113401002 pmid:10072409.

112 Chen Y-I, Barkun AN. Hemostatic powders in gastrointestinal bleeding: a systematic review. Gastrointest Endosc Clin N Am 2015;25:535-52. 10.1016/j.giec.2015.02.008 pmid:26142037.

113 Troland D, Stanley A. Endotherapy for peptic ulcer bleeding. Gastrointest Endosc Clin N Am 2018;28:277-89. 10.1016/. giec.2018.02.002 pmid:29933775.

114 Kyaw M, Tse Y, Ang D, Ang TL, Lau J. Embolization versus surgery for peptic ulcer bleeding after failed endoscopic hemostasis: a meta-analysis. Endosc Int Open 2014;2:E6-14. 10.1055/s-0034 1365235 pmid:26134614

115 Beggs AD, Dilworth MP, Powell SL, Atherton H, Griffiths EA. A systematic review of transarterial embolization versus emergency surgery in treatment of major nonvariceal upper gastrointestinal bleeding. Clin Exp Gastroenterol 2014;7:93-104. 10.2147/CEG. S56725 pmid:24790465.

116 Lau JYW, Pittayanon R, Wong KT, et al. Prophylactic angiographic embolisation after endoscopic control of bleeding to high-risk peptic ulcers: a randomised controlled trial. Gut 2018; gutjnl-2018-316074. 10.1136/gutjnl-2018-316074. pmid:29802172.

117 Cook D, Laine L. Indications, technique, and complications of balloon tamponade for variceal gastrointestinal bleeding. I Intensive Care Med 1992;7:212-8. 10.1177/088506669200700408 pmid:10147943.

118 Escorsell À, Pavel O, Cárdenas A, et al. Variceal Bleeding Study Group. Esophageal balloon tamponade versus esophageal stent in controlling acute refractory variceal bleeding: A multicenter randomized, controlled trial. Hepatology 2016;63:1957-67. 10.1002/ hep.28360 pmid:26600191.

119 Sung JJ, Luo D, Wu JC, et al. Early clinical experience of the safety and effectiveness of Hemospray in achieving hemostasis in patients with acute peptic ulcer bleeding. Endoscopy 2011;43:291-5. 10.1055/s0030-1256311 pmid:21455870.

120 Smith LA, Stanley AJ, Bergman IJ, et al. Hemospray application in nonvariceal upper gastrointestinal bleeding: results of the Survey to Evaluate the Application of Hemospray in the Luminal Tract. / Clin Gastroenterol 2014;48:e89-92.10.1097/MCG.054. pmid:24326829.

121 Sulz MC, Frei R, Meyenberger C, Bauerfeind P, Semadeni GM, Gubler C. Routine use of Hemospray for gastrointestinal bleeding: prospective two-center experience in Switzerland. Endoscopy 2014;46:619-24. 10.1055/s-0034-1365505 pmid:24770964.

122 Changela K, Papafragkakis H, Ofori E, et al. Hemostatic powder spray: a new method for managing gastrointestinal bleeding. Therap Adv Gastroenterol 2015;8:125-35. 10.1177/1756283X15572587 pmid:26082803.

123 Kwek BEA, Ang TL, Ong PLJ, et al. TC-325 versus the conventional combined technique for endoscopic treatment of peptic ulcers with highrisk bleeding stigmata: A randomized pilot study. J Dig Dis 2017;18:323 9. 10.1111/1751-2980.12481. pmid:28485544.

124 Ibrahim M, El-Mikkawy A, Abdel Hamid M, et al. Early application of haemostatic powder added to standard management for oesophagogastric variceal bleeding: a randomised trial. Gut 2018;gutjnl-2017-314653.10.1136/ gutjnl-2017-314653. pmid:29730601.

125 Schmidt A, Gölder S, Goetz M, et al. Over the scope clips are more effective than standard endoscopic therapy for patients with recurrent bleeding of peptic ulcers. Gastroenterology 2018;155:674-686.e6. 10.1053/j.gastro.2018.05.037. pmid:29803838.

126 Jensen DM, Kovacs TOG, Ohning GV, et al. Doppler endoscopic probe monitoring of blood flow improves risk stratification and outcomes of patients with severe nonvariceal upper gastrointestinal hemorrhage. Gastroenterology 2017;152:1310-1318.e1. 10.1053/j. gastro.2017.01.042 pmid:28167214 
STATE OF THE ART REVIEW

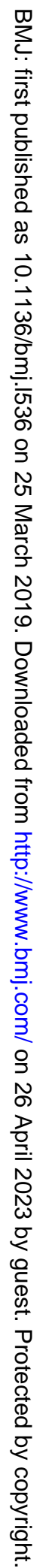


STATE OF THE ART REVIEW

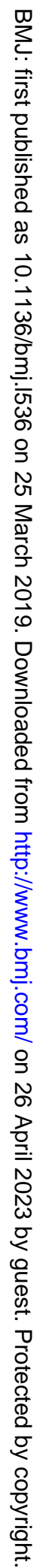

